\title{
Environmental-Friendly Mortar Produced with Treated and Untreated Coal Wastes as Cement Replacement Materials
}

Mostafa Soltaninejad ( $\triangle$ mostafa.soltaninejad2016@gmail.com )

Jacobs Engineering Group Inc https://orcid.org/0000-0003-1922-6619

Mosleh Soltaninejad

Islamic Azad University

Mohammadreza Khosravi Moshizi

Islamic Azad University

Vahid Sadeghi

Babol Noshirvani University of Technology

Farshad Saberi.K

Missouri S\&amp;T: Missouri University of Science and Technology

Peyman Jahanbakhsh

Islamic Azad University Najafabad Branch

\section{Research Article}

Keywords: Coal waste binders, Environmental impact evaluation, Sulfuric acid attack, Durability, Ettringite, Microstructure

Posted Date: March 10th, 2021

DOl: https://doi.org/10.21203/rs.3.rs-233737/v1

License: (c) (i) This work is licensed under a Creative Commons Attribution 4.0 International License.

Read Full License 


\section{Abstract}

This study aims to examine the influence of untreated coal waste (UCW) and treated coal waste (TCW) as supplementary cementitious materials (SCMs) on the environmental, mechanical, durability, and microstructural characteristics of mortar mixes. UCW preparation procedure consists of sequential steps of crushing and grinding. Afterward, UCW is thermally activated through incinerating at $750^{\circ} \mathrm{C}$ to be promoted to TCW. Experimental work includes mixing mortar mixtures by partially replacing cement with the coal waste binders (UCW and TCW) at different incorporation levels of $4,8,12$, and $16 \%$ of cement weight. Toxicity characteristic leaching procedure (TCLP) test was applied to investigate the environmental impacts of coal wastes. TCLP test results pointed out that heavy metals including Manganese, Cadmium, Lead, and Chromium could successfully entrap in the cement matrix. The compressive and flexural strengths as mechanical characteristics of mortar mixtures were determined at $3,7,28,90$, and 180 curing days. Moreover, the mortar specimens were immersed in $3 \%$ sulfuric acid $\left(\mathrm{H}_{2} \mathrm{SO}_{4}\right)$ for 60 and 150 days. Durability results showed that the $\mathrm{H}_{2} \mathrm{SO}_{4}$ attack resistance of binary cement mortars containing $4 \%$ coal waste binders was better than the plain mortar. Based on the scanning electron microscopy (SEM) images, ettringite was found as the main hydration product of binary cement after 28 days; however, the existence of calcium silicate hydrate (CSH) and calcium hydroxide $\left(\mathrm{Ca}(\mathrm{OH})_{2}\right)$ in the cement matrix of mixes after 90 days explains the more compact microstructure attained by using coal waste as cement replacement materials compared to control mixtures.

\section{Introduction}

\subsection{Environmental impacts of coal waste}

Nowadays, the production of waste materials is increasing, threatening human health and the environment around the world. Industry and technology development and the world population growth accelerated global solid waste materials (Karimipour et al. 2020). Coal as a fundamental energy asset is anticipated to account for half of the worldwide energy utilization in 2030 (Modarres et al. 2018). Based on the US energy information Administration (EIA), five countries, including the USA, Russia, Australia, China, and India, hold about $75 \%$ of the world's proved coal reserves. The world produces over 7.4 billion tons of coal per year, which about $15-20 \%$ is stockpiled as coal waste (Mejia-Ballesteros et al. 2019). Coal waste is a solid by-product and is generally made out of clay minerals and carbon (Frías et al. 2012). Coal mining waste has become a severe ecological and environmental concern (Karimipour et al. 2020), especially acid mine drainage.

Acid mine drainage (AMD) runoff is the most dangerous water contamination of coal mines. AMD comprises a substantial quantity of iron, $\mathrm{SO}_{4}{ }^{2-}$, and various quantities of poisonous heavy metals such as arsenate and copper with a toxic structure that contaminates water (Adhikari and Mal, 2021). Indeed, the problem of coal waste pollution is caused by pyrite oxidation. In essence, the oxidation of pyrite is the main reason for acidic water through pyretic exposure. In the study of surrounding water samples 
exposed to coal wastes, pyrite oxide and AMD runoff were observed (Hesami et al. 2016). The impact of coal waste on the surrounding environment is destructive because it forms deforestation, occupation of land, air pollution, and seepage of noxious waste into groundwater.

A study conducted by Ardejani et al. (2011) on coal waste landfills revealed physical changes in the surface water (Doulati Ardejani et al. 2010). Also, the leaching test findings indicated the concentration of noxious heavy metals. Furthermore, the $\mathrm{SO}_{4}$ concentration was higher than the allowable limit. It should be mentioned that AMD sludge has also been reported neighboring water of coal mines. Besides, coal waste comprises hazardous heavy metals, including Chromium (Cr), Cadmium (Cd), Lead (Pb), Nickel $(\mathrm{Ni})$, Zinc ( $\mathrm{Zn})$, Copper ( $\mathrm{Cu})$, and Manganese $(\mathrm{Mn})$. As an example of the toxic impact of these heavy metals, Mn has a neurotoxicological effect on human health, particularly on embryos and neonates (Adhikari and Mal, 2021).

\subsection{Supplementary cementitious materials (SCMs) as a sustainable solution}

The composition of greenhouse gases consists of $81 \%$ carbon dioxide $\left(\mathrm{CO}_{2}\right), 10 \%$ methane, $7 \%$ nitrous oxide, and $2 \%$ fluorinated gases (USEPA, 2018). Globally, 35 billion metric tons of $\mathrm{CO}_{2}$ was released in 2020 and is projected to increase to 43 billion metric tons by 2050 (Statista, 2021). Thus, $\mathrm{CO}_{2}$ has a significant impact on global warming. The production of cement consumes energy extensively and is solely responsible for $7 \%$ of the overall atmospheric $\mathrm{CO}_{2}$ emissions (Afrakoti et al. 2020; Sagheb et al. 2011), resulted from 1.6 billion tons of cement production worldwide (Afrakoti et al. 2020). Supplementary cementitious materials (SCMs) is known as a sustainable solution that can be replaced partially with cement (Hesami et al. 2016). Partially replacing cement with SCMs reduces environmental pollution, decreases the cost of cementitious products, and consumes by-products or wastes; therefore, it helps progress towards sustainable construction (Sakir et al. 2020). SCMs are usually incorporated with clinker or as a partial cement substitute. In addition, they can be simply combined with clinker. The application of these materials can result in environmentally friendly, high-strength, and durable mixes.

Million tons of by-products are stockpiled counted as solid waste materials. Using these waste materials as a partial replacement of binder in concrete is an economical, ecological, and green remedy to save natural resources (Li et al. 2020b). According to the literature ( $\mathrm{Li}$ et al. 2020b; Afrakoti et al. 2020; Saeidi Rashk Olia and Perić, 2020; Mejia-Ballesteros et al. 2019; Hassan et al. 2019; Haghani et al. 2019; Modarres et al. 2018; Kočí et al. 2016; Hesami et al. 2016; Ramezanianpour, 2014; Frías et al. 2012), previous studies have examined the cement substitution by SCMs, such as fly ash, rice husk ash, waste ceramic dust, coal waste, and other human-made wastes materials. It is worth mentioning that the particle size of SCMs has a direct impact on the mechanical properties of hardened mortar. For instance, the mortar incorporated with $8 \%$ ultra-fine fly ash $(3.4 \mu \mathrm{m})$ as a cement substitution delivered $23 \%$ higher compressive strength than the control mortar and revealed a higher strength up to $15 \%$ cement substitution (Sakir et al. 2020). 


\subsection{Literature review of coal waste}

Coal waste has previously been utilized as coarse and fine aggregates (Karimipour et al. 2020; Karimaei et al. 2020), as well as the partial replacement of cement in various applications, including soil stabilization (Afrakoti et al. 2020), road subgrade (Shirin et al. 2020), asphalt pavements (Ameli et al. 2020), concrete blocks (Dos Santos et al. 2013), fired bricks (Taha et al. 2018), concrete pavements (Shamsaei et al. 2019; Hesami et al. 2016), and mortar mixtures (Frías et al. 2012). Considering previous researches, using untreated coal waste in soil stabilization enhanced mechanical properties over time (Afrakoti et al. 2020). Frías et al. (2012) used the incinerated coal waste (i.e., treated coal waste) at 10\% and $20 \%$ cement substitution in mortar mixes (Frías et al. 2012). Their research showed that the mortar mixture containing $10 \%$ treated coal waste improved compressive strength negligibly at 7 days in comparison to the plain specimen; conversely, at 28 and 90 days, an average lower strength of $10 \%$ and $11 \%$ were observed, respectively. Additionally, this by-product was investigated by Hesami et al. (2016) in roller compacted concrete pavement as partial replacement of cement at incorporation levels of 5,10 , and $20 \%$. They reported specimens with $5 \%$ untreated coal waste (i.e., raw coal waste) outperformed compressive strength in comparison to the plain sample after 7,28, and 90 days of curing. Contrary, Shamsaei et al. (2019) reported a reduction in mechanical properties of mixes with untreated coal waste as SCM up to $5 \%$ replacement level.

The notion of applying treated and untreated coal waste materials as SCMs in the cement industry is still a novel research area and needs more studies to predict the environmental and technical performance of asphalt or concrete mixtures using coal waste. According to the literature, there is a huge gap in understanding the performance of this new SCM at early and late ages, specifically determining an environmentally sustainable and durable optimum content to assure the construction benefits of it.

In this study, coal waste materials were gathered from the Zarand coal washing plants located in the Kerman province, southeast of Iran. Currently, more than 6 million tons of coal waste materials are piled up in the dumping areas and the sedimentary basins near the coal washing plant. Annually, the amounts of the added wastes are projected to be more than 400,000 tons (Yaghubpour and Hakkakzadeh, 2010), and the coal waste volume is exponentially rising. The current experimental research was conducted with consideration to the environmental impact evaluation, mechanical properties (compressive and flexural strengths) of mortar mixtures during curing time, 3, 7, 28, 90, and 180 days, durability examination of 60day and 150-day mortar mixtures, and microstructural analysis of 28- and 90-day mixtures to assure the feasibility of using untreated and treated coal waste in construction projects.

\section{Experimental Procedure}

The experimental process of this research is illustrated in Fig. 1. It should be notified that the pozzolanic reactivity of UCW and TCW were analyzed. The main laboratory tests of this research have focused on (1) environmental impact assessment to evaluate the amount of heavy metals on the mortar leakage, (2) mechanical properties (i.e., compressive and flexural strengths) to test hardened mortars, (3) durability 
property of mortars containing coal waste materials to examine their resistance when exposed to the sulfuric acid solution, (4) microstructure analysis to evaluate the effect of coal waste binders on cement hydration.

\subsection{Materials}

The fine aggregate (sand) properties were chosen corresponding to the ASTM C778, and its physical properties are listed in Table 1. In addition, the sand gradation is displayed in Fig. 2. Type II Portland cement was utilized compatible with ASTM C150. Table 2 represents the chemical and physical properties of the studied cementitious binders. The chemical composition was determined with respect to ASTM E1621. The particle size distributions of cement and the SCMs are plotted in Fig. 3. The particle sizes of UCW was roughly coarser than cement particles. In contrast, TCW had finer particles compared to cement, which supports pozzolanic reactivity [2], particularly lead to a significant enrichment in the pozzolanic reactivity (Tironi et al. 2013).

Table 1

Physical properties of sand and associated standards

\begin{tabular}{|lll|}
\hline Test & Result & Standard \\
\hline Saturated surface dry (SSD) water absorption & $1.9 \%$ & ASTM: C1403 \\
Sand equivalent & $80 \%$ & ASTM: D2419 \\
\hline Fineness modulus & $2.87 \%$ & ASTM: C33 \\
\hline
\end{tabular}


Table 2

Chemical analysis and physical properties of the cementitious materials

\begin{tabular}{|llll|}
\hline & \multicolumn{3}{l}{ Cementitious materials } \\
\cline { 2 - 3 } & Cement & UCW & TCW \\
\hline (A) Chemical compositions $(w t . \%)$ & & & \\
\hline Silica $\left(\mathrm{SiO}_{2}\right)$ & 20.8 & 32.2 & 51.4 \\
\hline Alumina $\left(\mathrm{Al}_{2} \mathrm{O}_{3}\right)$ & 3.45 & 16.5 & 25.1 \\
\hline Iron oxide $\left(\mathrm{Fe}_{2} \mathrm{O}_{3}\right)$ & 3.66 & 4.22 & 8.24 \\
\hline Magnesium oxide $(\mathrm{MgO})$ & 3.29 & 1.25 & 1.97 \\
\hline Calcium oxide $(\mathrm{CaO})$ & 62.3 & 3.41 & 5.36 \\
\hline Sulfur trioxide $\left.(\mathrm{SO})_{3}\right)$ & 2.66 & 0.70 & 0.14 \\
\hline Sodium oxide $\left(\mathrm{Na}_{2} \mathrm{O}\right)$ & 0.78 & 0.52 & 1.80 \\
\hline Potassium oxide $\left(\mathrm{K}_{2} \mathrm{O}\right)$ & 0.71 & 1.62 & 2.47 \\
\hline Loss on ignition $(\mathrm{LOI})$ & 1.84 & 37.6 & 1.87 \\
\hline Total & 99.5 & 98.1 & 98.3 \\
\hline (B) Physical properties & & & \\
\hline Specific gravity $\left(\mathrm{g} / \mathrm{cm}{ }^{3}\right)$ & 3.24 & 2.42 & 2.22 \\
\hline Specific surface area $\left(\mathrm{m}^{2} / \mathrm{kg}\right)$ & 311 & 832 & 1266 \\
\hline
\end{tabular}

\subsubsection{Activating process of treated coal waste}

The weight loss of a substance such as rice husk ash after burning at high temperatures up to $1000{ }^{\circ} \mathrm{C}$ is described as Loss on Ignition (LOI) (Hesami et al. 2016). According to Table 2, the LOI of untreated coal waste was $37.6 \%$, which did not meet the boundaries indicated in ASTM C618. In this study, to decrease the LOI level, coal waste was ignited at various temperatures. Accordingly, the LOI content became steady at temperatures above $750^{\circ} \mathrm{C}$; therefore, this temperature was designated as the activated temperature.

\subsubsection{Pozzolanic activity analysis of SCMs}

The Chapelle test is a straightforward method to analyze pozzolanic activity based on NF P 18-513. In this approach, for a pozzolanic material, a minimum amount of $700 \mathrm{mg}$ calcium hydroxide per gram of a pozzolan is required to be consumed (Ferraz et al. 2014). The results showed that the UCW could not 
meet the requirement and have a lower value in comparison to the allowable limit. Although the raw coal waste (untreated coal waste) could not pass the requirement to be considered as pozzolan since it showed low reactivity, it contributed to the cement hydration process as a filler. Considering the Chapelle test results, TCW consumed more calcium hydroxide value than a standard limit. Consequently, TCW could be used as an SCM with high pozzolanic activity.

\subsection{Methods}

\subsubsection{Mix design and specimen preparation of mortar samples}

Cement pastes and mortar mixtures were prepared according to ASTM C305. Table 3 presents the the replacement proportions of cement with UCW and TCW. A total of nine mixtures were designed and tested, including control mixtures. The substitution dosages of cement with UCW and TCW were obtained as $4,8,12$, and $16 \%$. Mortar prisms were prepared by sand/binder ratio of $3 / 1$ and water/binder ratio of 0.5. To perform each test, at least three identical samples were produced in each batch to test, and the average value was reported.

Table 3

The replacement level of studied SCMs in cement pastes and mortar mixtures

\begin{tabular}{|llll|}
\hline \multirow{2}{*}{ Mixture ID } & \multicolumn{3}{l}{ Cementitious materials (wt.\%) } \\
\cline { 2 - 4 } & Cement & UCW & TCW \\
\hline Control & 100 & 0 & 0 \\
\hline UCW-4 & 96 & 4 & 0 \\
\hline UCW-8 & 92 & 8 & 0 \\
\hline UCW-12 & 88 & 12 & 0 \\
\hline UCW-16 & 84 & 16 & 0 \\
\hline TCW-4 & 96 & 0 & 4 \\
\hline TCW-8 & 92 & 0 & 8 \\
\hline TCW-12 & 88 & 0 & 12 \\
\hline TCW-16 & 84 & 0 & 16 \\
\hline
\end{tabular}

For mechanical tests, cubic and prism samples were used. The compressive strengths were assessed by casting mortar in 135 cubes of $50 \times 50 \times 50 \mathrm{~mm}^{3}$, then cured at $20 \pm 1^{\circ} \mathrm{C}$, and finally stored at $95 \%$ relative humidity in a standard curing box for $24 \mathrm{~h}$. After $24 \mathrm{~h}$, mortar specimens were removed from the molds and cured in saturated limewater at $20 \pm 2{ }^{\circ} \mathrm{C}$ until specified testing time of $3,7,28,90$, and 180 
days. Similarly, the flexural strengths were evaluated by producing 135 prisms of $40 \times 40 \times 160 \mathrm{~mm}^{3}$ cured for $3,7,28,90$, and 180 days. After performing the mechanical tests, a part of the mortar sample was immersed into ethanol to end the hydration of cement composites for scanning electron microscope (SEM) tests. SEM is a qualitative technique for microstructure analysis. For the durability test, 54 cubic specimens of $50 \times 50 \times 50 \mathrm{~mm}^{3}$ were prepared. After 28 days of normal curing, the samples were fully soaked in $3 \% \mathrm{H}_{2} \mathrm{SO}_{4}(\mathrm{pH}=0.6)$ solutions to simulate erosion damage until the exposure ages of 60 and 150 days.

\subsubsection{Toxicity characteristics leaching procedure (TCLP) test}

The toxicity characteristics leaching procedure (TCLP) test is a standard technique developed by the US environmental protection agency so as to indicate the ability of waste materials to leach heavy metals into groundwater (USEPA, 1992). In this method, the buffer of $1 \mathrm{M}$ sodium acetate was used as an extraction fluid, and the $\mathrm{pH}$ was held at 4.99. In a glass bottle, a 20:1 solid-ratio extraction solution was taken and mounted in a rotary shaker at $30 \pm 2 \mathrm{rpm}$ at $25^{\circ} \mathrm{C}$ for $18 \mathrm{~h}$. Afterward, using Whatman No. $42-$ grade filter paper, the solutions were filtered and then analyzed. A substance is known as a hazardous material on the basis of the TCLP test if any found metals are detected at concentrations above 100 times the drinking water standard (Disfani et al. 2012). For instance, the allowable limit of $\mathrm{Mn}$ in drinking water is $0.1 \mathrm{mg} / \mathrm{L}$ (Adhikari and Mal, 2021), which is acceptable for non-hazardous materials to be up to $10 \mathrm{mg} / \mathrm{L}$ since it is based on the threshold for hazardous waste defined by US EPA.

\subsubsection{Mechanical tests}

In this study, mechanical properties (compressive and flexural strengths) of cement mortar incorporating UCW and TCW were reported at ages of 3, 7, 28, 90, and 180 days in accordance with ASTM C109 and ASTM C348, respectively. The tests were accomplished using an automatic electronic universal testing machine. Concerning ASTM C109, the loading rate must be between 0.9 to $1.8 \mathrm{KN} / \mathrm{s}$. Therefore, the loading rate of $1.2 \mathrm{KN} / \mathrm{s}$ was employed for the compressive test. Considering ASTM C348, the loading rate of $2.64 \pm 0.11 \mathrm{KN} / \mathrm{s}$ must be applied. The flexural strength test was carried out with a loading rate of $2.7 \mathrm{KN} / \mathrm{s}$.

\subsubsection{Sulfuric acid resistance test}

To evaluate the durability of mortar samples, the resistance to sulfuric acid $\left(\mathrm{H}_{2} \mathrm{SO}_{4}\right)$ attack test was conducted consistent with ASTM C267. The examined parameters were the residuals of compressive strength and mass of the samples after exposing to sulfuric acid. According to previous studies (Vafaei et al. 2021; Abdel-Gawwad et al. 2021; Khan et al. 2019), the concentration of 3\% sulfuric acid was selected to model the aggressive atmosphere of the sewer structure. The residual mass and the compressive strength were recorded after 60 and 150 days of acid solution exposure.

\subsubsection{Scanning electron microscopy (SEM) test}


SEM images were employed to discuss the microstructure of hardened mortar specimens containing waste cementitious materials (i.e., UCW and TCW) at 28 and 90 days. To take SEM micrographs, an LEO 1400 microscope was used, as shown in see Fig. 4. For the preparation of SEM specimens, $10 \times 10 \times 3$ $\mathrm{mm}^{3}$ dried paste was prepared and used.

\section{Results And Discussion}

\subsection{Environmental impact evaluation of coal waste 3.3.1. TCLP test results}

To assure that using coal waste in mortar is environmentally friendly, firstly, the environmental impact of it should be controlled before investigating the technical properties. Noteworthy, TCLP is employed recently to estimate the heavy metal concentration of coal mining dumps (Adhikari and Mal, 2021; Taha et al. 2018). In this investigation, the TCLP test was utilized to examine the environmental effect of coal waste binders (i.e., UCW and TCW) before and after use in the mortar mixtures. Figure 5 shows the TCLP results of UCW (raw coal waste), TCW (ignited coal waste), and AMD (acid mine drainage sludge) of the studied coal washing plant in comparison to the allowable levels specified by EPA SW846-1311 (USEPA, 1992). The concentrations of seven heavy metals, including $\mathrm{Mn}, \mathrm{Cd}, \mathrm{Pb}, \mathrm{Cu}, \mathrm{Ni}, \mathrm{Cr}$, and $\mathrm{Zn}$, were measured. Based on Fig. 5, the concentration of $\mathrm{Mn}, \mathrm{Pb}, \mathrm{Cr}$, and $\mathrm{Cd}$ were more than the US-EPA thresholds. It is worth mentioning that the TCW leachate concentrations of heavy metals were greater in comparison to those of the UCW and AMD runoff.

TCLP test was also performed for crushed hardened mortar specimens after 28 days of curing, and the results are depicted in Fig. 6 . The heavy metal concentrations were all below the permissible limits for mortar mixtures. The concentration of heavy metals in mortar samples containing TCW was higher compared to those containing UCW, analogous to coal waste binder samples. It should be noted that some of the leaching concentration of control mixes did not detect in the test due to the small amount of heavy metal.

\subsubsection{Effect of cement matrix on entrapping the heavy metals}

Toxic heavy metals of waste materials could be entrapped physically and bind chemically by the cement matrix (Khater and Ghareib, 2020; Argane et al. 2015). Likewise, a comparison of TCLP results of the waste cementitious materials pre- (Fig. 5) and post- (Fig. 6) employing in the mortar mixes indicated that the cement hydrate products could substantially stabilize and solidify the heavy metals. According to the literature (Argane et al. 2016; Haibin and Zhenling, 2010) [8,34,35], it has been stated that the capacity of cement matrix in stabilizing a significant quantity of heavy metals can also improve mechanical properties. 
Figure 7 depicts the concentration of heavy metal and the percentage of the heavy metal removal ratio with reference to the primary content for $\mathrm{Mn}, \mathrm{Cd}, \mathrm{Cr}$, and $\mathrm{Pb}$ since these heavy metals had higher concentrations than the US-EPA threshold (Fig. 5). As shown in Fig. 7, the removal ratio in heavy metals concentration was mostly more than $85 \%$ (Figs. 7(a), (b), (e), (f), (g)), and (h)). The maximum solidification was observed for $\mathrm{Cr}$ by more than $90 \%$ removal ratio (Figs. $7(\mathrm{e})$, and (f)), and the minimum stabilization was reported for Cd with a 57\% reduction in mixes with UCW (Fig. 7(c)); however, mixes with TCW showed a better performance in entrapping Cd by more than $65 \%$ removal rate (Fig. 7 (d)).

Although TCW was detected with higher heavy metal compared to UCW (Fig. 5), the heavy metal removal of mixes with TCW performed better than mixes with UCW (Fig. 6). The analysis between the results of TCLP in the coal waste binders pre and post use in the mortar samples found that the cement hydrate products in the mortar mixes could considerably solidify and stabilize the UCW and TCW heavy metals and limit the secondary possible problem of using them, which is the leakage of heavy metals.

\subsection{Mechanical properties results \\ 3.2.1. Compressive strength}

Compressive strength is a major property of concrete structures for design purposes. The compressive strength of mortar mixtures at $3,7,28,90$, and 180 days is demonstrated in Fig. 8. As displayed in the figure, the maximum compressive strength was attained for TCW-8 containing $8 \%$ TCW, equaling to 19.2 , $27.5,34.6,43.0$, and $48.8 \mathrm{MPa}$ at ages of $3,7,28,90$, and 180 days, respectively. Noticeably, mortar mixtures containing 4\% UCW (UCW-4) and 4\% TCW (TCW-4) also outperformed plain mortar at all ages, especially at the age of 180 days by about $12 \%$ and $15 \%$, respectively. The minimum 28 -day compressive strength is recommended to be equal to or more than 17.2 MPa based on ASTM C270 standard specification. Concerning this criterion, all mixes satisfied the minimum compressive strength requirement; thus, in terms of compressive strength concerns, mortar mixes containing waste cementitious materials are qualified to be used for construction purposes.

It should be notified that the test results also specified that increasing UCW content from 4-16\% dropped the compressive strength values drastically over time. For example, by increasing UCW content from 4$16 \%$ (UCW-4 and UCW-16), the compressive strength has dropped on an average of $37 \%$ at all ages. However, this strength drop was about $24 \%$ for mortars containing TCW. The strength drop of coal wastes in the mixtures might be as the result of heavy metals (Frías et al. 2012), since the presence of $\mathrm{Cr}$ and $\mathrm{Pb}$ concentrations in the coal waste was more than the regulatory limits specified by the US environmental protection agency (Modarres et al. 2018).

On the other hand, the continuous strength reduction of UCW mixtures was not observed for TCW mixtures since the compressive strength presents a pick at the mixture with $8 \% \mathrm{TCW}$ (TCW-8) because of higher strength value compared to $4 \% \mathrm{TCW}$ and control mixture. This strength enhancement is associated with several factors, such as the ongoing progression of the pozzolanic reaction that results in compressive strength enhancement (Frías et al. 2012). Due to the fact that TCW is a pozzolanic 
material (see Sect. 2.1.3), the better mechanical performance of TCW-4 and TCW-8 could be correlated with it. The filler effect is another factor that can explain the betterment of the compressive strength of hardened mortar with $4 \%$ UCW compared to the plain mixture. This improvement in the mechanical properties has previously been reported for coal waste concrete mixtures (Modarress et al. 2018). In essence, SCM particles provide nucleation centers for the precipitation of hydrated products that cause a denser paste (Avila-López et al. 2015). Last but not least, the particle size of SCMs affects strength gain (Sakir et al. 2020) because finer particles can provide more nucleation sites to fill the pores to accelerate the hydration reactions (Engbert and Plank, 2021). TCW has finer particles compared to UCW and cement materials (Fig. 3); thus, this might be another reason for the better performance of TCW mixes versus UCW and control mixtures.

\subsubsection{Flexural strength}

Flexural strength is considered an important parameter in designing concrete structures, such as bridges, concrete pavement, and building structures. The flexural strength test results at $3,7,28,90$, and 180 days are illustrated in Fig. 9. Based on this figure, the reported flexural strengths were between 1.53 and 6.42 $\mathrm{MPa}$. As illustrated in the figure and similar to compressive strength values, TCW-8 presents the maximum flexural strength among the mixes. Furthermore, UCW-4 and TCW-4 have higher flexural strength with respect to the control mixture. Figure 9 designates that rising the degree of cement replacement of SCMs from 4-16\% reduces flexural strengths. As an example, UCW content increase from $4-16 \%$, the flexural strength was dropped on average of $37 \%$ at all ages. However, similar to compressive strength, a pick was observed for mixes with TCW where flexural strength of TCW-8 was reported higher than TCW-4, about $10 \%$ at all ages. The minimum mortar flexural strength was observed in mixtures with 16\% UCW (UCW-16).

\subsubsection{Effect of coal waste materials on the toughness of hardened mortar}

For the judgment of the toughness of hardened mortar, compressive/flexural strength ratio is an important factor (Wang et al. 2005). Higher compressive/flexural strength (toughness) ratio represents higher toughness of mortar (Parghi and Shahria Alam, 2016). The toughness ratios of mortar mixes for various cementitious material content are displayed in Fig. 10. As shown in the figure, the toughness ratio rises with increasing the cementitious materials ratios up to $16 \%$, which contrasts with previous studies Parghi and Shahria Alam, 2016; Wang et al. 2005). The highest toughness for UCW mixes was observed after 28 days and for TCW mixes after 180 days. This difference might be due to the pozzolanic property of TCW in comparison with UCW that delays the strength gaining for mixes with TCW. The toughness ratio of studied mortar was between 6.8 to 9.5 , which is in the range of 3.5 to7.5 (Wang et al. 2005), and 4 to 10 (Parghi and Shahria Alam, 2016).

\subsubsection{Effect of curing time on the mechanical properties}

The logarithmic functions were plotted to find the connection between the curing period and compressive and flexural strengths, as displayed in Figs. 11-14. According to the figures, the logarithmic function 
could robustly predict the compressive and flexural strengths $\left(R^{2}>0.95\right)$. The curves for mortar mixtures with 4\% UCW (UCW-4), 4\% TCW (TCW-4), and 8\% TCW (TCW-8) show higher slopes than the control mix, especially for the mixtures with TCW at later curing times. This means that the differences between the mechanical properties of UCW-4, TCW-4, and TCW-8 samples were considerably accelerated over time compared to the control mixture. This increase could be associated with the delayed cement hydration stemmed from the pozzolanic reaction of SCMs with an exceptional surface area that reacts with calcium hydroxide $\left(\mathrm{Ca}(\mathrm{OH})_{2}\right)$ in the pore solution of cement paste to produce more hydration products (Pitarch et al. 2021).

Moreover, the mortar mixtures incorporated treated coal waste represent higher strength when compared with the mixtures incorporating cement and untreated coal waste at the same substitution dosages, especially for flexural strength. For instance, the difference of compressive strength for the mixes with $4 \%$ TCW (TCW-4) was about $6 \%$ and $3 \%$ compared to the mixes with $4 \%$ UCW UCW-4) at 90 and 180 days, respectively. This difference for flexural strength was reported $7 \%$ and $6 \%$ at 90 and 180 days, respectively. Considering the literature (Engbert and Plank, 2021; Celik et al. 2014), higher mechanical properties of mortar mixtures with UCW and TCW binders might be associated with the filler effect and nucleation sites, respectively, which accelerate the hydration reactions.

\subsection{Durability investigation}

Durability is one of the most critical components of concrete structures. Durable concrete resists under the attack of acids and sulfates to which concrete may be exposed (Vafaei et al. 2021). Nevertheless, ordinary concrete cannot resist acid attacks for a considerable period. When a concrete structure is exposed to an acidic environment, a neutralization reaction between $\mathrm{Ca}(\mathrm{OH})_{2}$ and hydrogen ion in the binders occurs (Usman and Sam, 2017). Then, calcium cations are leached from the calcium-comprising elements, like calcium silicate hydrate and Portlandite, into the acidic environment (Scrivener and Young, 1997). Therefore, the alkalinity reduction of concrete matrix and increase the total porosity leads to terminations of the hydration products that cause the concrete failure (Chen et al. 2013), and causing a significant reduction in the durability and mechanical characteristics of concrete (Scrivener and Young, 1997). Nonetheless, with the presence of pozzolanic materials in concrete, the $\mathrm{Ca}(\mathrm{OH})_{2}$ amount is diminished, and the microstructure is augmented due to micro-filling and pozzolanic impacts (Usman and Sam, 2017). Hence, the impermeability of acid solution that aggravates the harmful action of acid on concrete is drastically lowered.

\subsubsection{Residual compressive strength}

After immersion in the acid solution, the relative compressive strength of the mortars was obtained regarding the identical samples cured in limewater. The residual compressive strength is illustrated in Fig. 15. According to this figure, the compressive strength for all the samples declined after 150 days. Nonetheless, the rate of strength reduction of mixes with treated coal waste binders was less than the mortars with untreated coal waste. In general, cement mortars containing TCW had higher resistance to 
sulfuric acid attack than the mixes with UCW and control mortars at both exposure periods. After 150 days of exposure, the compressive strength of mortar mixes without coal waste binders (control), with $4 \%$ untreated coal waste (UCW-4), and with $4 \%$ treated coal waste (TCW-4), as shown in Fig. 15, decreased to 33,38 , and $40 \%$, respectively.

The higher resistance to the sulfuric acid attack of mortars with $4 \%$ coal waste (UCW-4 and TCW-4) compared to the control mortar can be attributed to the filler effect and pozzolanic activity of untreated and treated coal waste, respectively. Even though Sulfuric acid exposure changes the microstructure of the cement matrix by developing micro-cracks (Vafaei et al. 2021; Khan et al. 2019), the formations of more hydrates reinforce the microstructure and therefore lessens the rate of acid permeability into the mortar containing pozzolan (Usman and Sam, 2017). Correspondingly, the improvement in the cement matrix of mortars incorporated with pozzolanic materials such as fly ash, rice husk ash, and silica fume compared to plain mortar in the acidic environment has been declared in the previous studies (AbdelGawwad et al. 2021; Usman and Sam, 2017).

\subsubsection{Residual mass}

Figure 16 represents the residual masses of plain and mortars with coal waste binders immersed in the acid solution. All mortars showed a decline in their weight after the first 60 days of contact with the acid solution and continued up to 150 days. Nonetheless, the degree of lessening varies with increasing the mortar binder. Similar to the compressive strength scenario, mortars containing the UCW binders exhibited a higher decline in mass than that of with TCW mortars over time. It is worth mentioning that the plain mortar had the highest drop in mass. In this regard, at 150 days, the residual mass of control, UCW-4, and TCW-4 mortar specimens were 45,54 , and $56 \%$, respectively.

There are many reasons that can directly influence the mass drop of the samples. The first reason could be related to the partial leaching out of bulk cement paste stemmed from the dissolution action of sulfuric acid on the cement paste (Usman and Sam, 2017). Second, the hydration products shaped in the cement microstructure are decomposed because of the reaction of calcium with acidic anions, leading to a rise in total porosity and accelerating acid attack (Duan et al. 2015). In fact, $\mathrm{H}_{2} \mathrm{SO}_{4}$-exposed mortar containing anion sulfate results in developing the formation of gypsum. Subsequently, the induction of internal decomposing stresses and surface spalling could be expected (Sata et al. 2012). In other words, the lesser formation of gypsum in the hydration system results from the reduction of calcium hydroxide related to the higher pozzolanic activity of supplementary cementitious materials (Usman and Sam, $2017)$, leading to a reduction in mass of pastes. Also, the sum of oxide composition $\left(\mathrm{Al}_{2} \mathrm{O}_{3}+\mathrm{SiO}_{2}+\mathrm{CaO}\right)$ of the pozzolanic materials positively impacts the acid resistance of the hardened mortars (Vafaei et al. 2021), which is considerably higher in the chemical composition of coal waste binders since the values for cement, untreated coal waste, treated coal waste is $27.91,52.92$, and $84.74 \%$ of weight, respectively (based on Table 2).

\subsection{Microstructural observation}


Figs. 17 and 18 signify the SEM images of the hardened mortar specimens at the age of 28 and 90 days, respectively. Based on Fig. 17(a), the microstructure of the control mortar is different from the mixture containing coal waste materials. In the microstructure of the mix incorporated with 4\% UCW (Fig. 17(b)), the existence of ettringite (needle-like crystals) in the microstructure was considerable after 28 days compared to the control mixture (Fig. 17(a)). However, a spherical and denser microstructure could be seen for UCW-4 mortar mixes after 90 days of curing (Fig. 18(b)) in comparison to the control mixture (Fig. 18(a)) due to the presence of calcium silicate hydrate (gel-like flocks) and calcium hydrate (fibrouslike crystals). Previously, the formation of crystals of ettringite was observed in mortars containing supplementary cementitious materials as well (Nguyen et al. 2021; Li et al. 2020b), especially in the cement pastes with coal waste as a supplementary binder (Afrakoti et al. 2020). It should be noted that the enhancement of mechanical strength is attained by a considerably more compact microstructure where pore space between unreacted particles is completely filled with dense webs of ettringite crystallites resulted from SCMs (Nguyen et al. 2021). Furthermore, the improvement of CaO content, as well as the presence of a suitable proportion of calcium to pozzolanic materials diminish non-condensing crystals of ettringite and $\mathrm{CH}$ abundantly for mixes containing UCW (Afrakoti et al. 2020), as can be observed in Fig. 18(b) for UCW-4 mixture after 90 days of curing. On the other hand, the addition of UCW improves the connection between the cement paste and the sand grains, which plays an essential role in permeability, durability, and strength properties (Afrakoti et al. 2020).

As illustrated in Figs. 17(c) and (d), a considerable amount of ettringite also can be seen for TCW-4 and TCW-8 after 28 days of curing in comparison with UCW-4 (Fig. 18(b)) and control mortar (Fig. 17(a)). The microstructure of mortar mixes containing TCW binders is improved after 90 days (Figs. 18(c) and (d)) because of more hydration products such as calcium silicate hydrate and calcium hydrate. It has been reported that finer particles like TCW could enhanse the packing density of the cement matrix by developing the number of nucleation sites, led to an increase in the hydration products (Li et al. 2020b). The higher packing density can cause better mechanical properties of concrete mixes (Filimonov et al. 2021).

Moreover, the maximum packing density can be reached by dense particle size distribution, varying the particle size ratio between the large and small particles. It is possible that replacing cement with coal waste materials of the studied mortar mixes has modified the gradation of binders in the mortar mixes and results in improving the packing density and cement paste performance. The SEM images of mortar mix with coal waste binders attested to the improved structure of cement paste in comparison to the mixtures without these additives. Therefore, binary mixes containing coal waste powders formed a more integrated microstructure, especially for treated coal waste. It is noteworthy that the boosted mechanical properties of mortar mixes incorporated with treated coal waste binders are aligned with the microstructural analysis. To close, it needs to be emphasized that the use of UCW and TCW in mortar not only leads to standard mechanical, durability, and technical characteristics, but also it minimizes the volume of toxic waste deposits and their damaging impacts on nature. 


\section{Conclusions}

In this research, the effect of raw (untreated) coal waste and ignited (treated) coal waste as cement replacement materials in mortar. Herein, the following conclusions can be obtained:

- The environmental impact evaluation corroborates that the heavy metals were well solidified and stabilized by cement hydrate products.

- Mortar mixes containing 4\% UCW or TCW had better mechanical and durability performance, including compressive strength, flexural strength, and sulfuric acid resistance.

- The reduction in mass and compressive strength of mortars produced with the binary binders containing 4\% UCW (or 4\% TCW) were found lower than the plain mortar produced with ordinary cement in response to sulfuric acid attack. Hence, coal waste binders could be considered durable and practically be used in acidic environments such as concrete sewer pipes and wastewater treatment facilities.

- Considering environmental, mechanical, and durability assessment, the optimum replacement percentage of cement with coal waste binders (UCW and TCW) was established as $4 \%$.

- SEM observation provided evidence that typical hydration products including ettringite (needle-like crystals), calcium hydroxide (fibrous-like crystals), and calcium silicate hydrate (gel-like flocks) were observed in the cement matrix of mixes containing coal waste binders. The amount of ettringite in mixes containing UCW was considerable in comparison to the TCW and control mixture after 28 days. However, it was reduced after 90 days of curing.

In conclusion, utilizing untreated and treated coal waste in mortar can essentially lessen cement production. The environmental, mechanical, durability, and microstructural advantages of these supplementary cementitious materials certainly are aligned with the ultimate goal of sustainable and cleaner production.

\section{Declarations}

\section{Conflict of interest}

The authors have no conflicts of interest to declare that are relevant to the content of this article.

\section{References}

Abdel-Gawwad H A, Metwally K A, Tawfik T A, Mohammed M S, Hassan H S, Heikal M, El-Kattan I M (2021) Evaluating the performance of high volume fly ash-blended-cement mortar individually containing nano-and ultrafine micro-magnesia. J Build Eng: 102129 
Adhikari K, Mal U (2021) Evaluation of contamination of manganese in groundwater from overburden dumps of Lower Gondwana coal mines. Environ Earth Science 80(1):1-15

Argane R, Benzaazoua M, Hakkou R, Bouamrane A (2016) A comparative study on the practical use of low sulfide base-metal tailings as aggregates for rendering and masonry mortars. J Cleaner Pro 112:914925

Ardejani F D, Shokri B J, Bagheri M, Soleimani E (2010) Investigation of pyrite oxidation and acid mine drainage characterization associated with Razi active coal mine and coal washing waste dumps in the Azad shahr-Ramian region, northeast Iran. Environ Earth Science 61(8):1547-1560

Afrakoti M T P, Choobbasti A J, Ghadakpour M, Kutanaei S S (2020) Investigation of the effect of the coal wastes on the mechanical properties of the cement-treated sandy soil. Contr Build Mater 239:117848

Ameli A, Babagoli R, Norouzi N, Jalali F, Mamaghani F P (2020) Laboratory evaluation of the effect of coal waste ash (CWA) and rice husk ash (RHA) on performance of asphalt mastics and Stone matrix asphalt (SMA) mixture. Contr Build Mater 36:117557

Avila-López U, Almanza-Robles J M, Escalante-García J I (2015) Investigation of novel waste glass and limestone binders using statistical methods. Contr Build Mater 82:296-303

Chen M C, Wang K, Xie L (2013) Deterioration mechanism of cementitious materials under acid rain attack. Eng Fail Analysis 27:272-285

Dos Santos C R, do Amaral Filho J R, Tubino R M C, Schneider I A H (2013) Use of coal waste as fine aggregates in concrete paving blocks. Geomater 03:54-59

Disfani M M, Arulrajah A, Bo M W, Sivakugan N (2012) Environmental risks of using recycled crushed glass in road applications. J Cleaner Prod 20(1):170-179

Duan P, Yan C, Zhou W, Luo W, Shen C (2015) An investigation of the microstructure and durability of a fluidized bed fly ash-metakaolin geopolymer after heat and acid exposure. Mater Des 74:125-137

Engbert A, Plank J (2021) Impact of sand and filler materials on the hydration behavior of calcium aluminate cement. J Amer Ceramic Soc 104(2):1067-1075

Ferraz E, Andrejkovičová S, Velosa A L, Silva A S, Rocha F (2014) Synthetic zeolite pellets incorporated to air lime-metakaolin mortars: Mechanical properties. Contr Build Mater 69:243-252

Filimonov A M, Rogozin O A, Firsov D G, Kuzminova Y O, Sergeev S N, Zhilyaev A P, ... Evlashin S A (2021) Hardening of Additive Manufactured 316L Stainless Steel by Using Bimodal Powder Containing Nanoscale Fraction. Mater 14(1):115 
Frías M, De Rojas M S, García R, Valdés A J, Medina C (2012) Effect of activated coal mining wastes on the properties of blended cement. Cem Concr Compos 34(5):678-683

Haghani M, Jalalkamali R, Berangi M (2019) Assigning crashes to road segments in developing countries. Proc Inst Civil Eng-Trans 172 (5), 299-307

Hassan E M, Abdul-Wahab S A, Abdo J, Yetilmezsoy K (2019) Production of environmentally friendly cements using synthetic zeolite catalyst as the pozzolanic material. Clean Technol Environ Policy 21(9):1829-1839.

Hesami S, Modarres A, Soltaninejad M, Madani H (2016) Mechanical properties of roller compacted concrete pavement containing coal waste and limestone powder as partial replacements of cement. Contr Build Mater 111:625-636

Karimaei M, Dabbaghi F, Sadeghi-Nik A, Dehestani M (2020) Mechanical performance of green concrete produced with untreated coal waste aggregates. Contr Build Mater 233: 117264

Karimipour A (2020) Effect of untreated coal waste as fine and coarse aggregates replacement on the properties of steel and polypropylene fibres reinforced concrete. Mech Mater 150:103592

Khan H A, Castel A, Khan M S, Mahmood A H (2019) Durability of calcium aluminate and sulphate resistant Portland cement based mortars in aggressive sewer environment and sulfuric acid. Cem Concr Res 124:105852

Khater H M, Ghareib M (2020) Optimization of geopolymer mortar incorporating heavy metals in producing dense hybrid composites. J Build Eng 32:01684

Kočí V, Maděra J, Jerman M, Žumár J, Koňáková D, Čáchová M, Černý R (2016) Application of waste ceramic dust as a ready-to-use replacement of cement in lime-cement plasters: an environmental-friendly and energy-efficient solution. Clean Technol Environ Policy 18(6): 1725-1733

Li S S, Liu H, Bharath M S, Zhang S X, Cheng X (2020a) Variation in the sulfate attack resistance of iron rich-phosphoaluminate cement with mineral admixtures subjected to a Na2SO4 solution. Constr Build Mater 230: 116817

Li X, Ma Y, Shen X, Zhong Y, Li Y (2020b) Study of Hydration and Microstructure of Mortar Containing Coral Sand Powder Blended with SCMs. Mater 13(19): 4248

Liu R., Yang Y, Zhao X, Pang B (2021) Quantitative phase analysis and microstructural characterization of Portland cement blends with diatomite waste using the Rietveld method. J Mater Sci 56(2): 1242-1254

Mejia-Ballesteros J E, Savastano Jr H, Fiorelli J, Rojas M F (2019) Effect of mineral additions on the microstructure and properties of blended cement matrices for fibre-cement applications. Cem Con Comp 98:49-60 
Modarres A, Hesami S, Soltaninejad M, Madani H (2018) Application of coal waste in sustainable roller compacted concrete pavement-environmental and technical assessment. Int J Pave Eng 19(8):748-761

Nguyen H, Kunther W, Gijbels K, Samyn P, Carvelli V, Illikainen M, Kinnunen P (2021) On the retardation mechanisms of citric acid in ettringite-based binders. Cem Con Res 140:106315

Parghi A, Shahria Alam M (2016) Effects of curing regimes on the mechanical properties and durability of polymer-modified mortars-an experimental investigation. J Sus Cem-Based Mater 5(5):324-347

Pitarch A M, Reig L, Tomás A E, Forcada G, Soriano L, Borrachero M V, Monzó J M (2021) Pozzolanic activity of tiles, bricks and ceramic sanitary-ware in eco-friendly Portland blended cements. J Cleaner Prod 279:123713

Ramezanianpour A A (2014) Cement replacement materials. Springer-Verlag, Berlin Heidelberg Saeidi Rashk Olia A, Perić D (2021) Thermo-Mechanical Soil Structure Interaction in Single Energy Piles Exhibiting Reversible Interface Behavior Int J Geomech

Sagheb A, Vafaeihosseini E, Ramancharla P K (2011) The role of building construction materials on global warming: lessons for architects. In National Con Recent Trends Civil Mechl Eng

Sakir S, Raman S N, Safiuddin M, Kaish A B M, Mutalib A A (2020) Utilization of By-Products and Wastes as Supplementary Cementitious Materials in Structural Mortar for Sustainable Construction. Sustain 12(9):3888

Sata V, Sathonsaowaphak A, Chindaprasirt P (2012) Resistance of lignite bottom ash geopolymer mortar to sulfate and sulfuric acid attack. Cem Con Comp 34(5):700-708

Scrivener K L, Young J F (Eds.) (1997) Mechanisms of chemical degradation of cement-based systems. CRC Press

Shamsaei M, Khafajeh R, Aghayan I (2019) Laboratory evaluation of the mechanical properties of roller compacted concrete pavement containing ceramic and coal waste powders. Clean Technol Environ Policy 21(3):707-716

Shirin M S, Islam M M, Kumruzzaman M (2020) Stabilization of Coal Mine Waste and Its Practical Application as a Road Subgrade. Amer J Traf Trans Eng 5(5):51-56

Statista. (2021) [online] Available at: https://www.statista.com/statistics/263980/forecast-of-globalcarbon-dioxide-emissions/

Taha Y, Benzaazoua M, Edahbi M, Mansori M, Hakkou R (2018) Leaching and geochemical behavior of fired bricks containing coal wastes. J Environ Manag 209:227-235 
Tironi A, Trezza M A., Scian A N, Irassar E F (2013) Assessment of pozzolanic activity of different calcined clays. Cem Conc Comp 37:319-327

USEPA, (1992) Method 1311 - toxicity characteristic leaching procedure [online]. US EPA. Available from: http://www.epa.gov/sw-846/pdfs/1311.pdf

USEPA (2018) Greenhouse Gas Emissions [online]. US EPA. Available from:

https://www.epa.gov/ghgemissions/overview-greenhouse-gases

Usman J, Sam A M (2017) Acid resistance of palm oil fuel ash and metakaolin ternary blend cement mortar. Sustain Environ Res 27(4):181-187

Vafaei M, Allahverdi A, Dong P, Bassim N, Mahinroosta M (2021) Resistance of red clay brick waste/phosphorus slag-based geopolymer mortar to acid solutions of mild concentration. J Build Eng 34:102066

Wang R, Wang P M, Li X G (2005) Physical and mechanical properties of styrene-butadiene rubber emulsion modified cement mortars. Cem Con Res 35(5):900-906

Yaghubpour A, Hakkakzadeh B (2010) Environmental effects of the Zarand coal mines and coal washing plant in Kerman Province, Southeast Iran. Mineral Mag

\section{Figures}




\section{Experimental program}

\section{Material properties}

- Plot sand aggregate gradation curve in accordance with ASTM C33

- Present chemical and physical analysis of cement, UCW, and TCW

- Depict particle size distribution of cement, UCW, and TCW

- Describe activating process of treated coal waste due to LOI reduction

- Evaluate pozzolanic reactivity of coal waste materials by Chapelle test

\section{Mix design and specimen preparation}

- Prepare cement pastes and mortars according to ASTM C305

- Determine the incorporation levels of cement with UCW and TCW

- Allocate cement pastes proportions and mix design of mortar mixtures

- Determine water to cementitious ratios to cast the samples

- Prepare beam and cubic shaped specimens to extract the test results

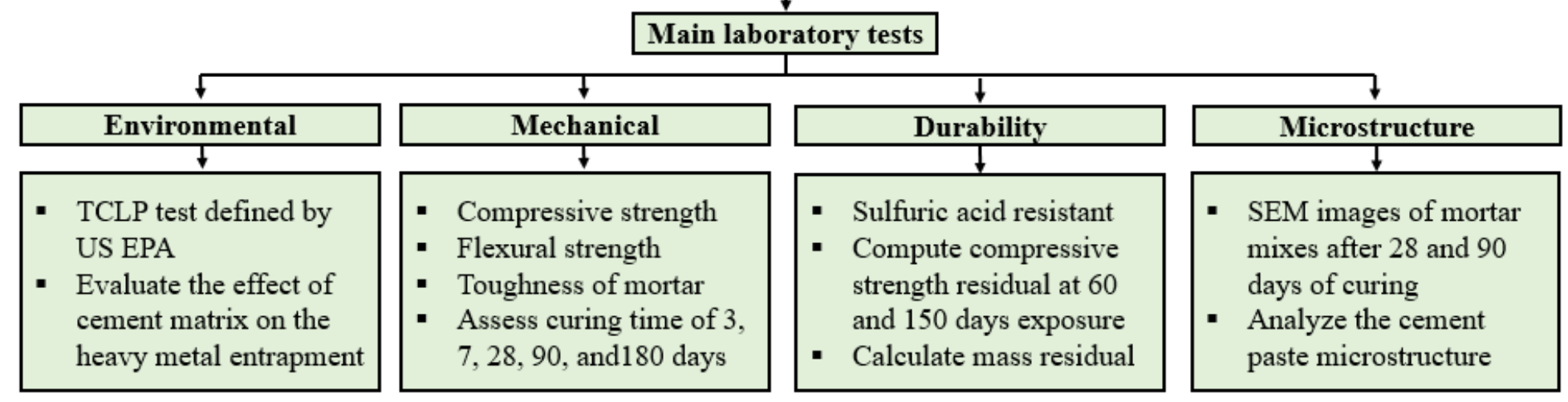

Figure 1

The summarized experimental program of this research

\section{-•ASTM C33 Standard limits}

-Grading of fine aggregates

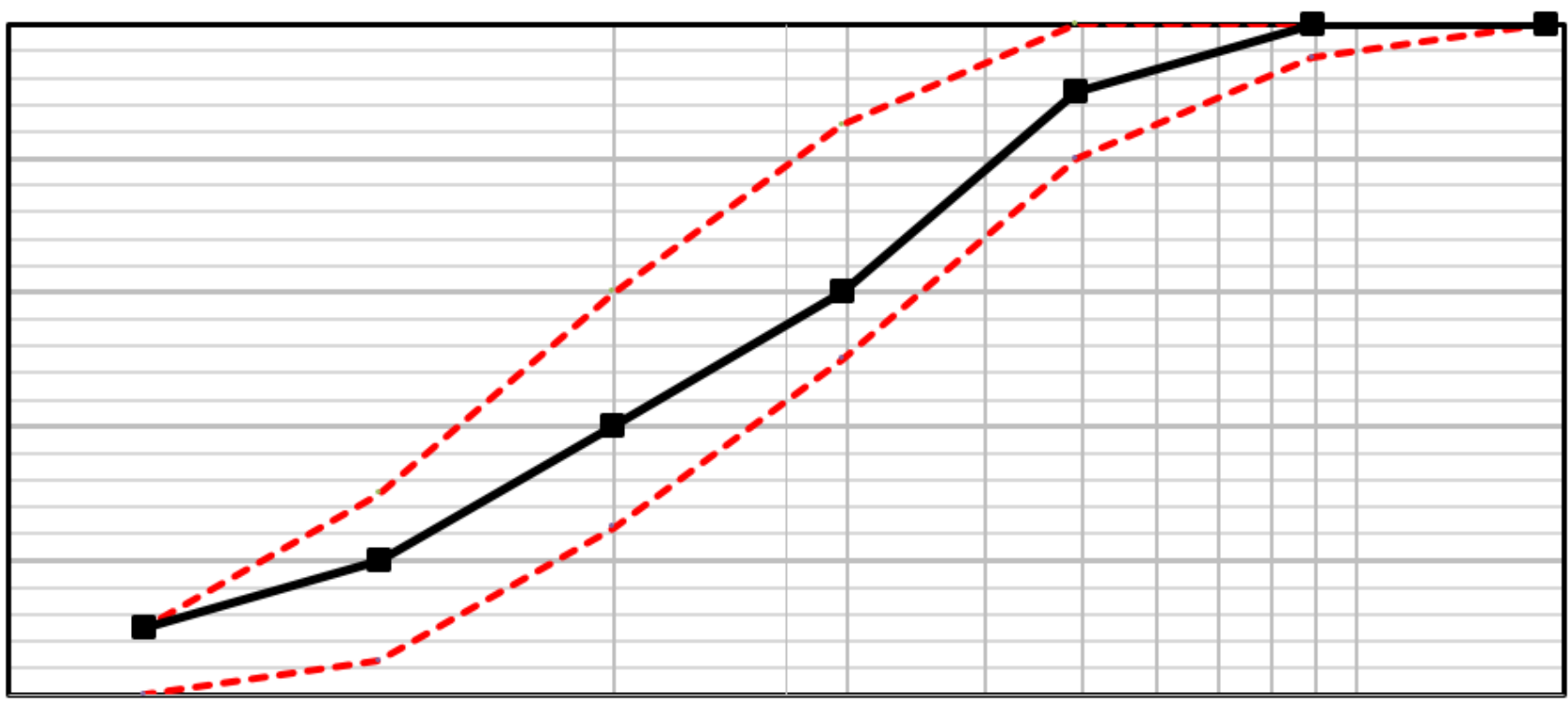

0.1 
Figure 2

Sieve analysis of fine aggregates (sand) in accordance with ASTM C33 standard limits

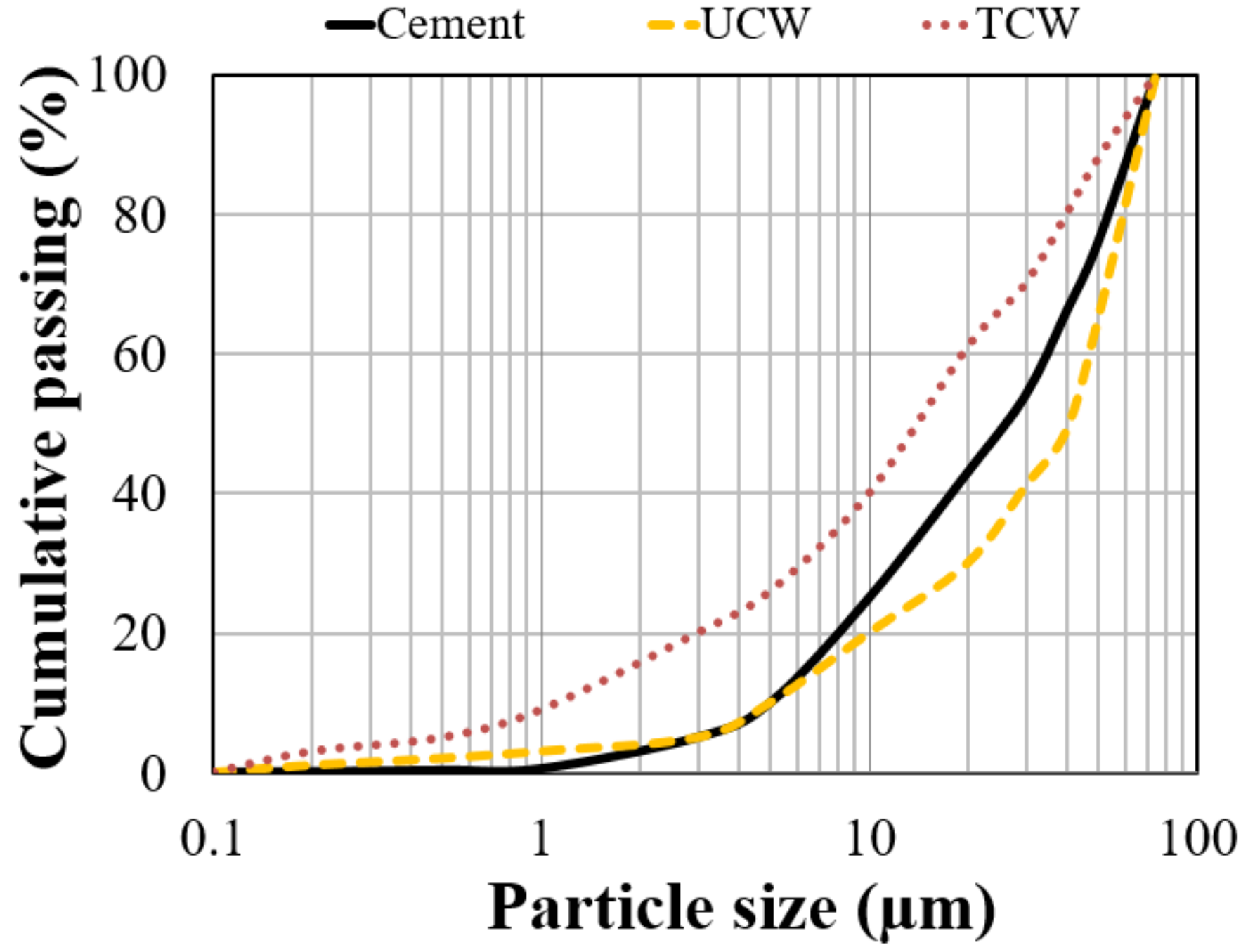

Figure 3

Particle size distribution of cement, UCW, and TCW 


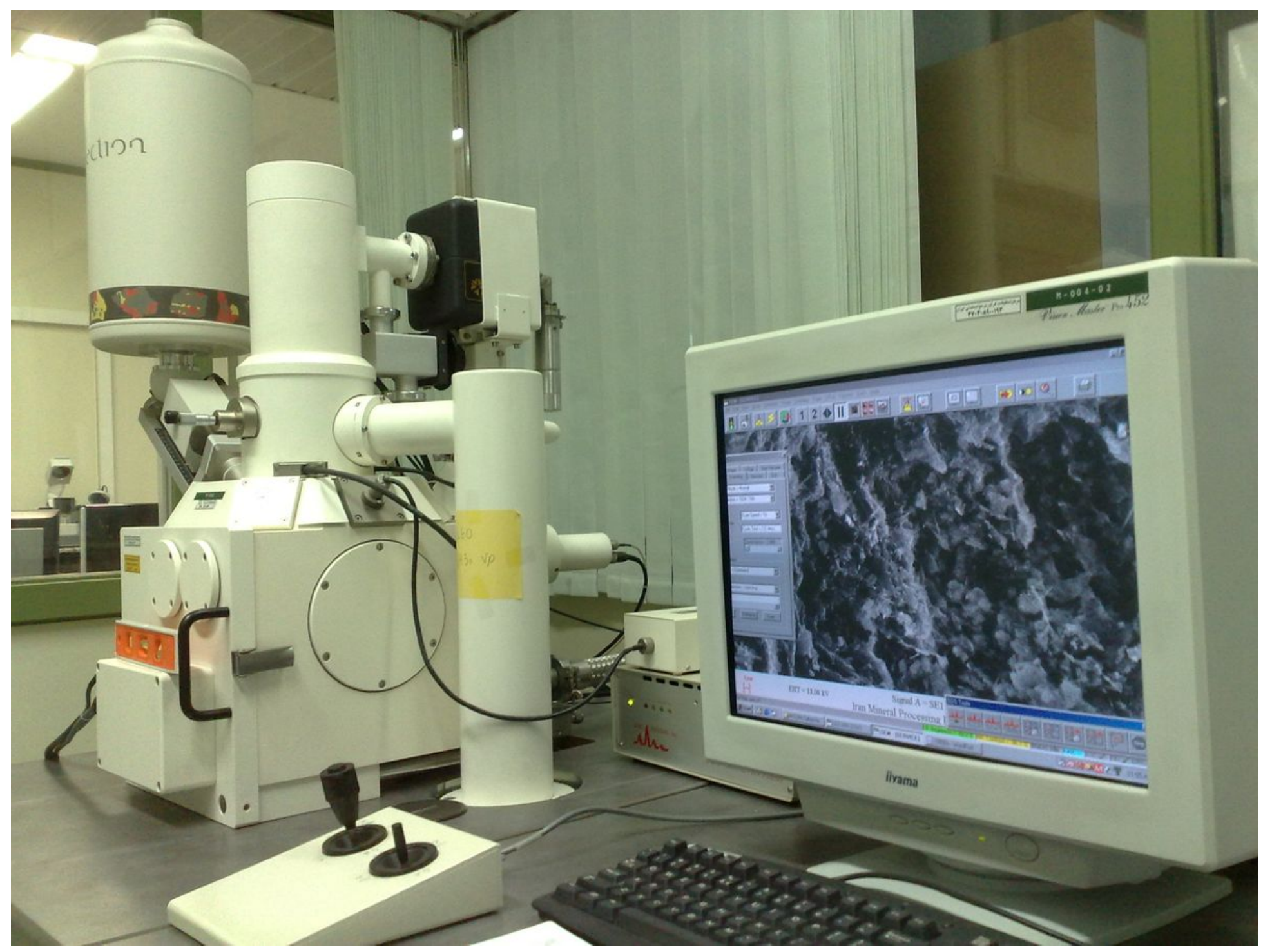

Figure 4

SEM apparatus employed in this study to take micrographs 


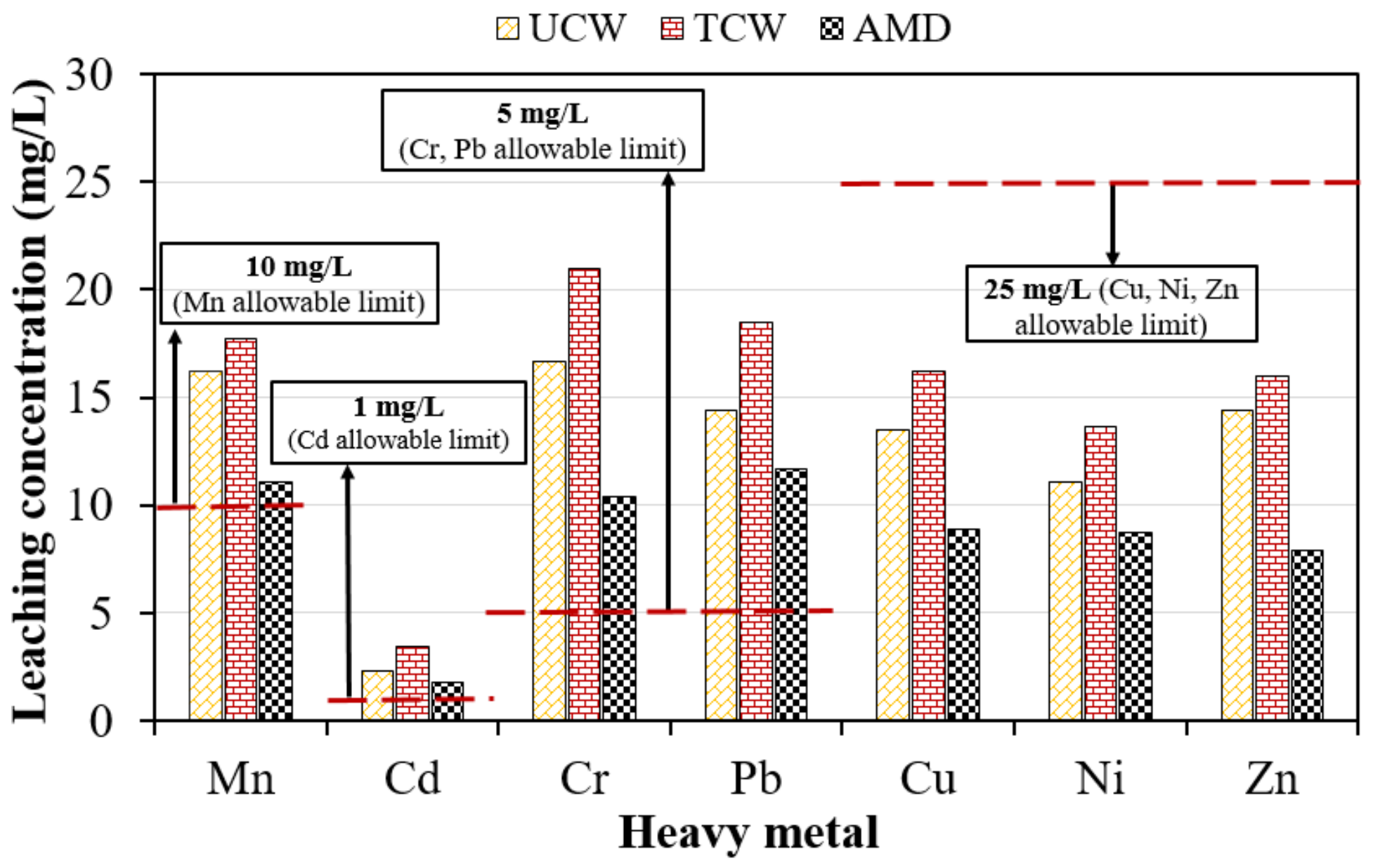

Figure 5

Heavy metal concentration of UCW, TCW, and AMD sludge after 28 days 


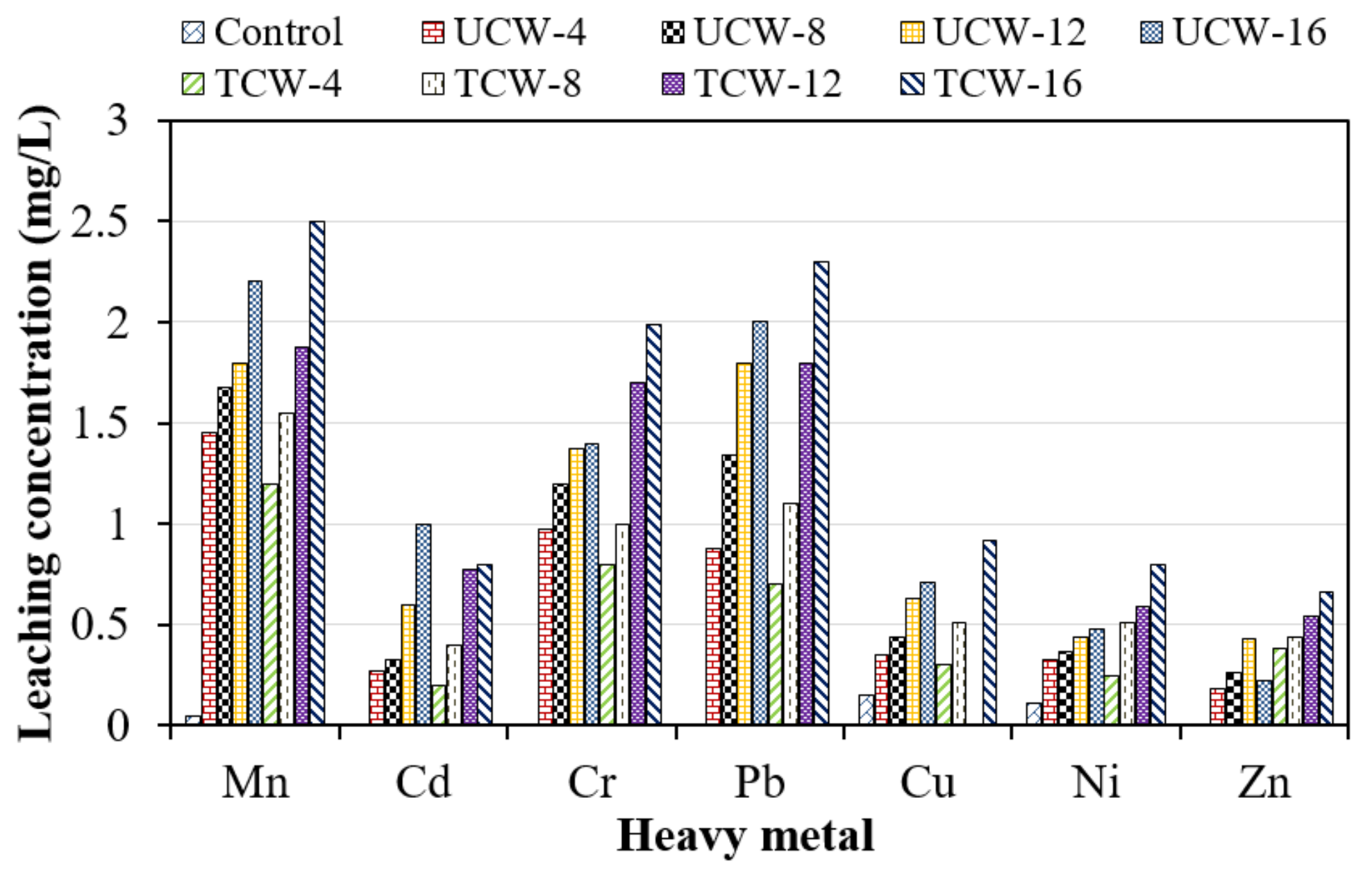

Figure 6

Heavy metal concentration of mortar mixes containing waste binders after 28 days 

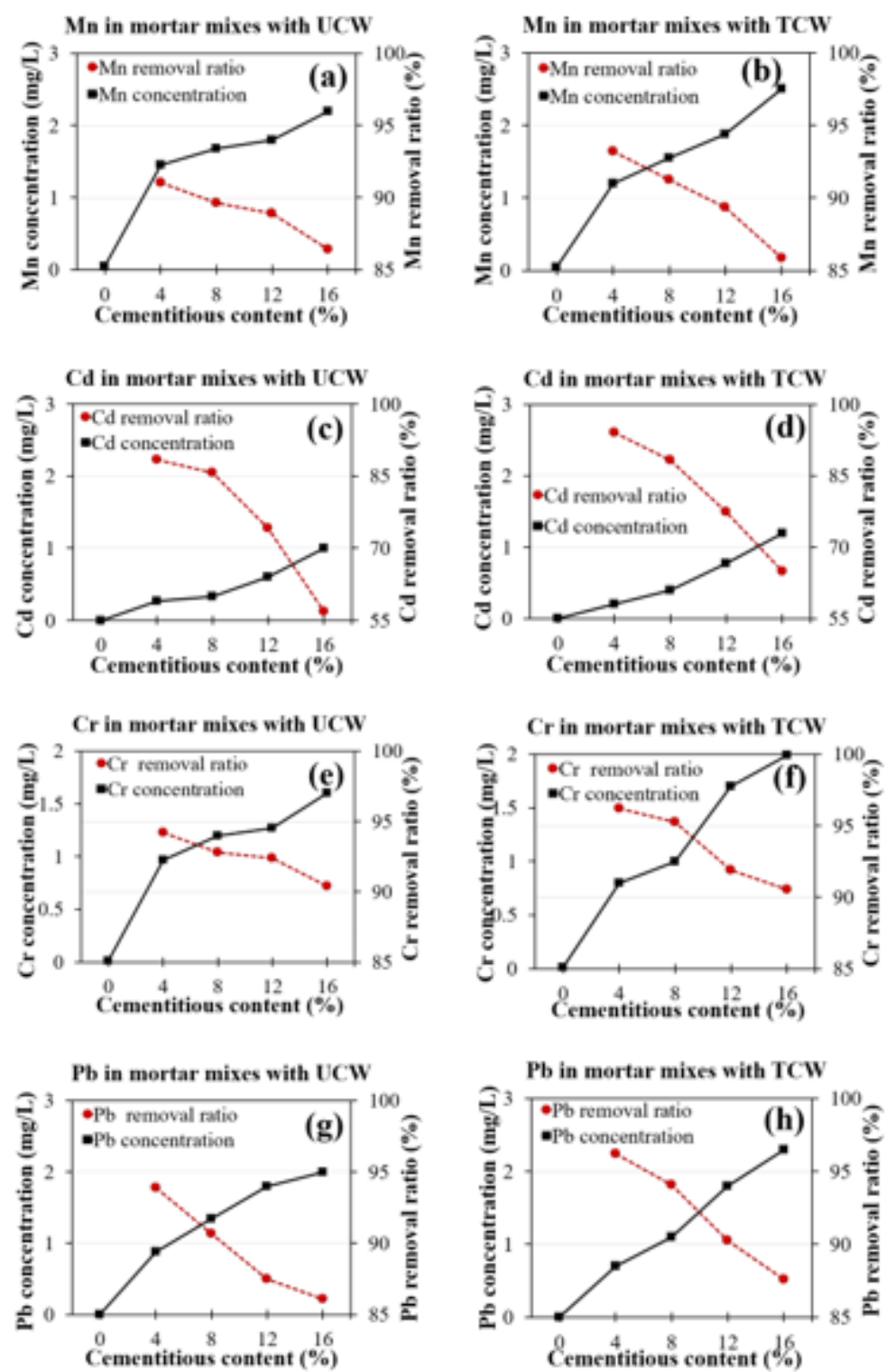

$\mathrm{Pb}$ in mortar mixes with TCW

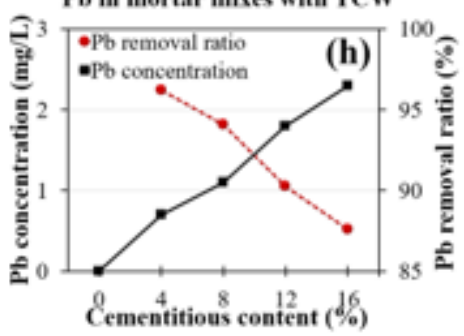

Figure 7

Heavy metal concentration and removal ratio for mortar mixes after 28 days 


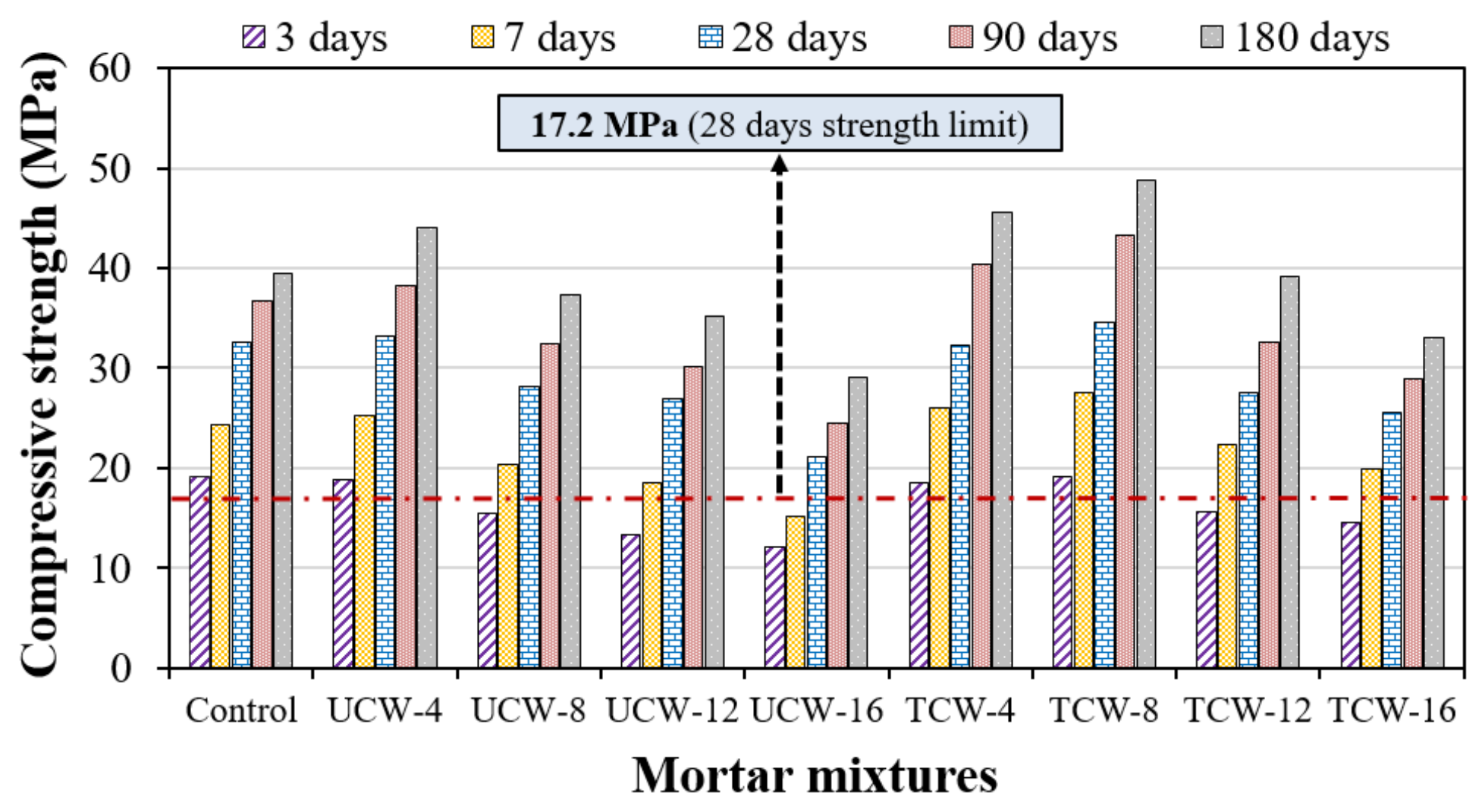

Figure 8

Compressive strength of mortar samples at different cement replacement levels and curing time

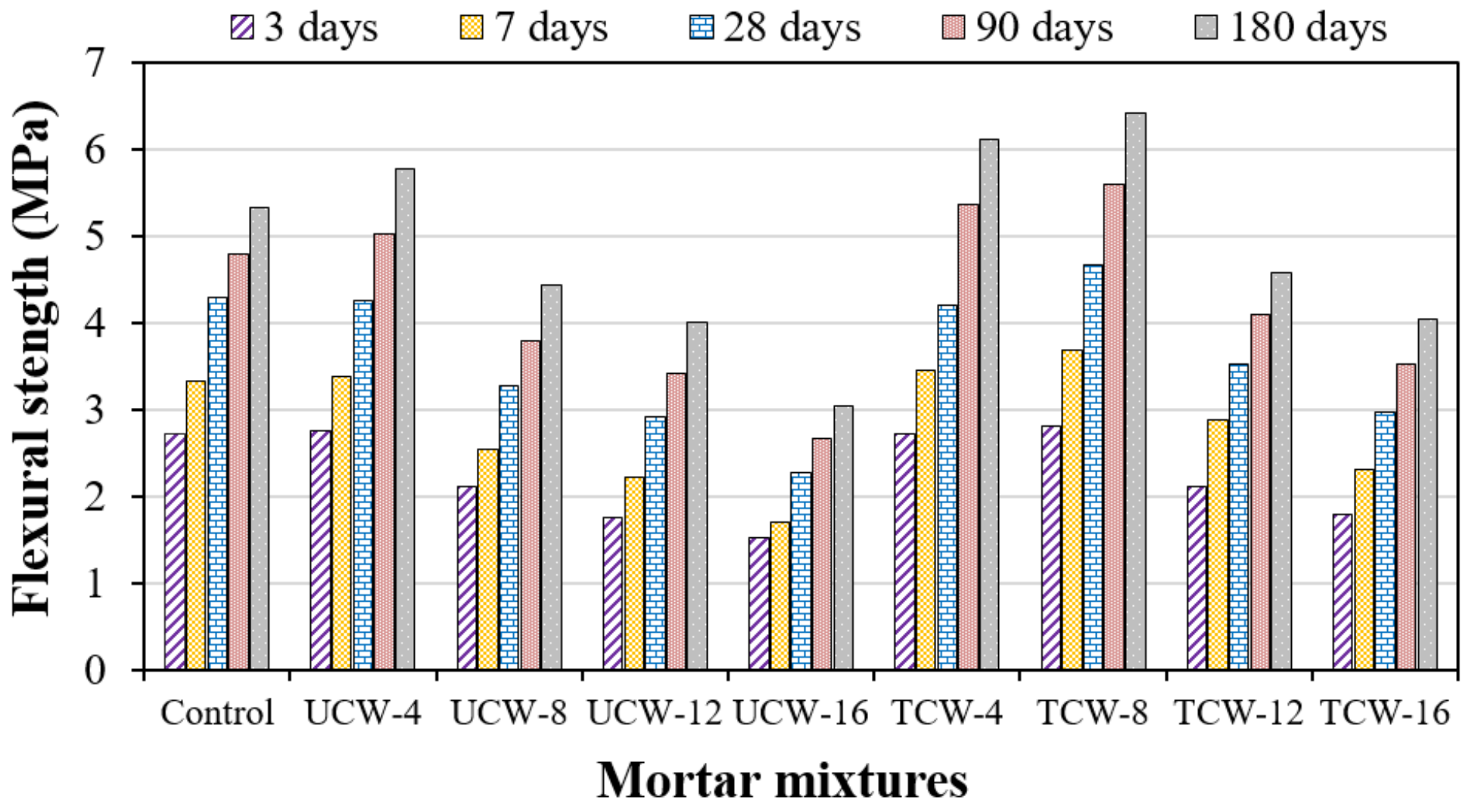

Figure 9 
Flexural strength of mortar samples at different cement replacement levels and curing time
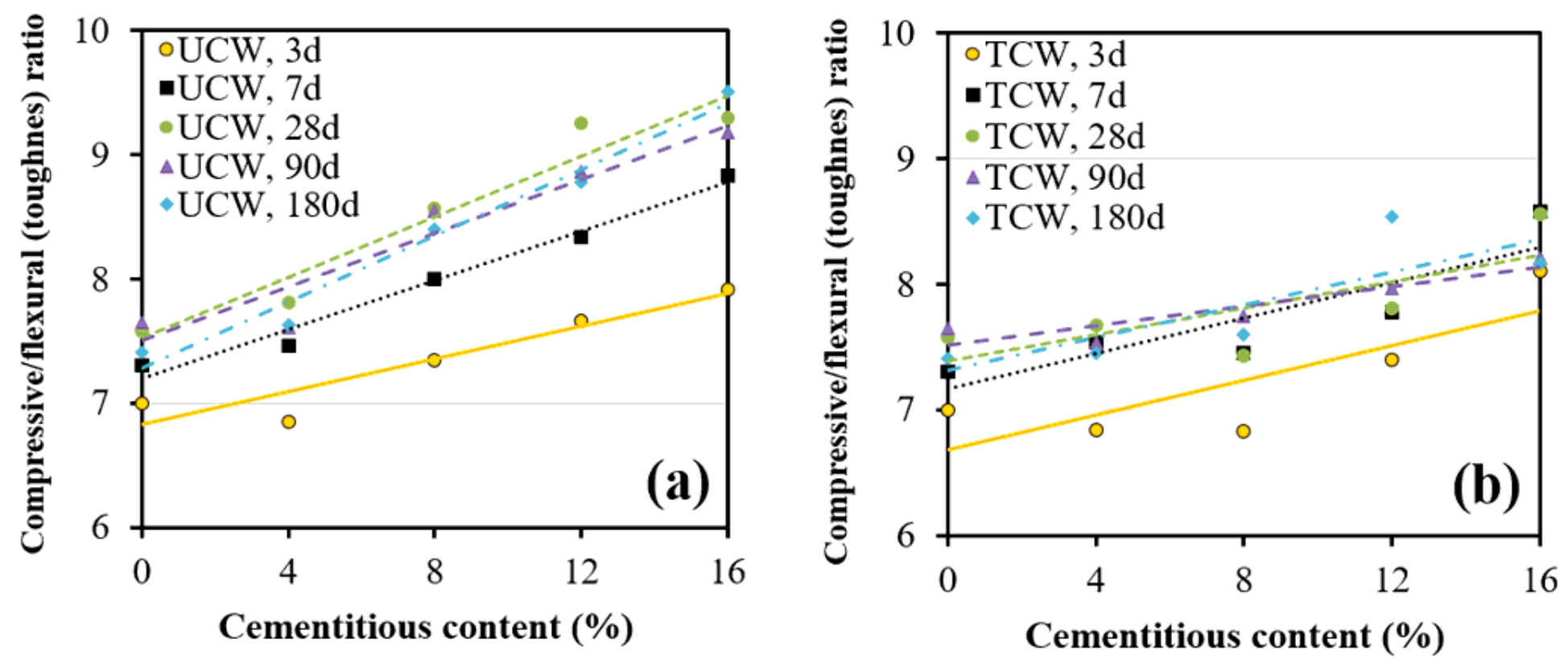

Figure 10

Compressive to flexural strength (Toughness) ratio of mortars containing (a) untreated coal waste (UCW), and (b) treated coal waste (TCW) over time

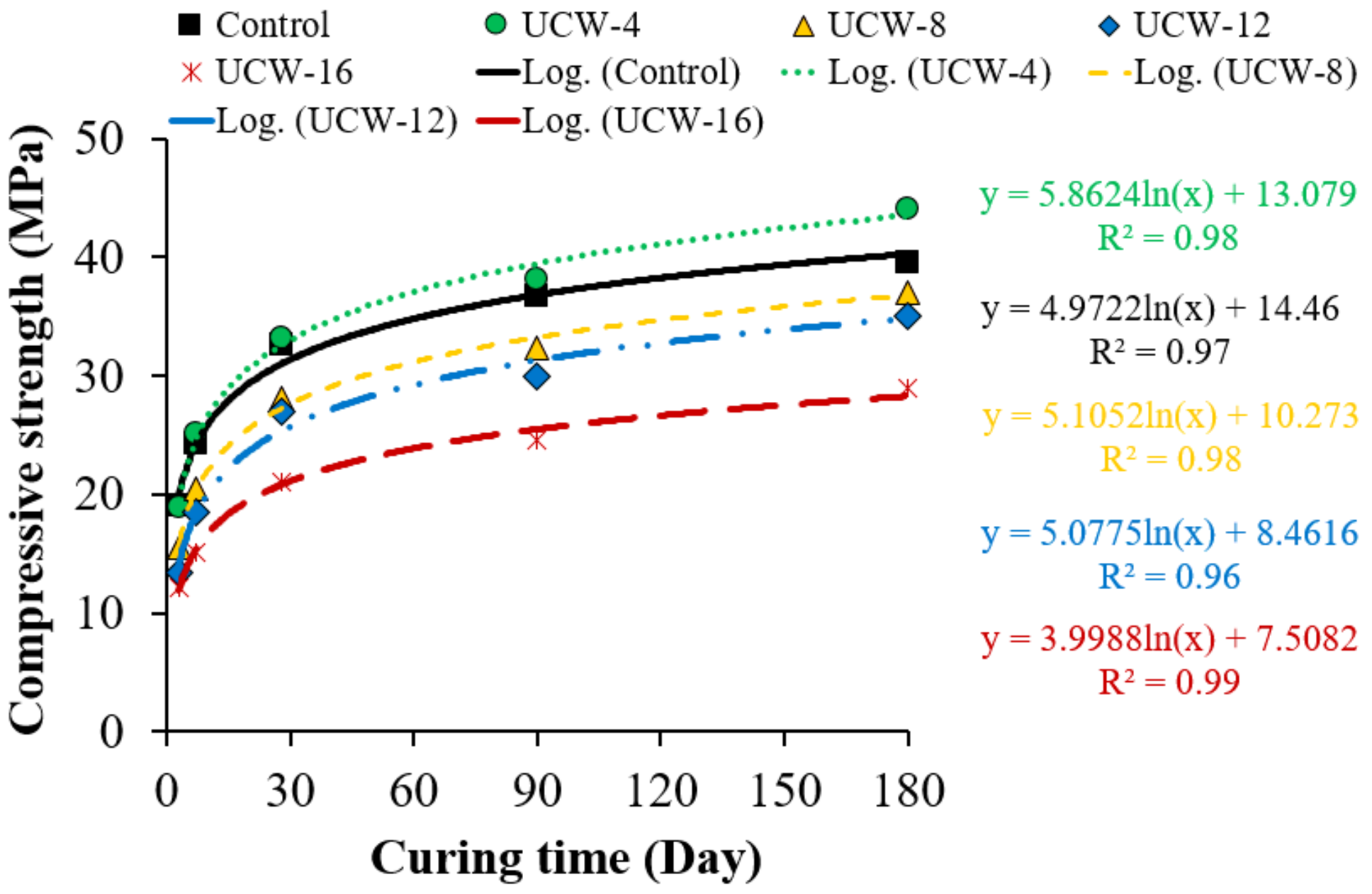


Figure 11

Relationship between curing time (x) and compressive strength (y) of mortar mixtures containing UCW in comparison with the control mix

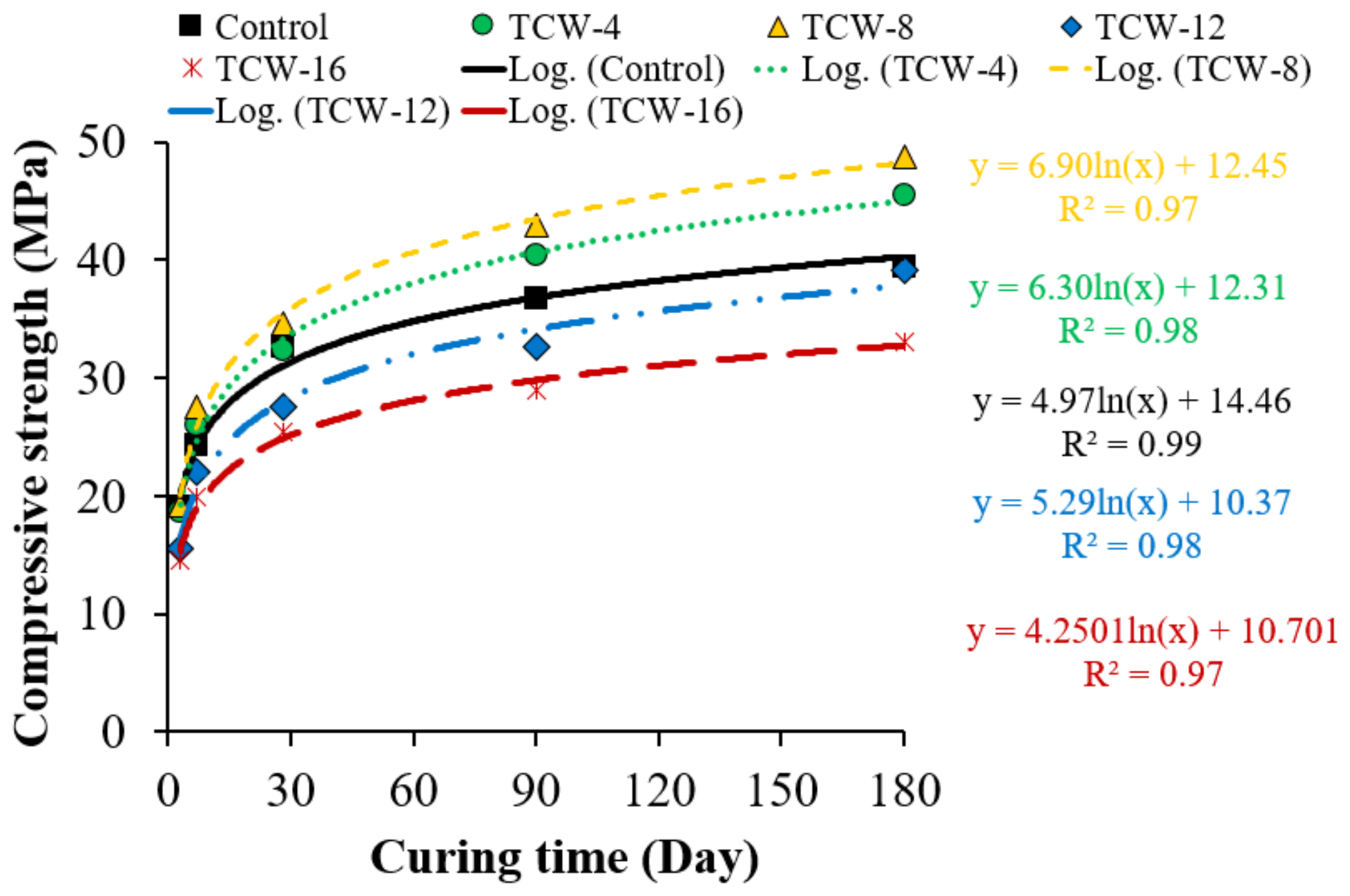

Figure 12

Relationship between curing time $(\mathrm{x})$ and compressive strength $(\mathrm{y})$ of mortar mixtures containing TCW in comparison with the control mix 


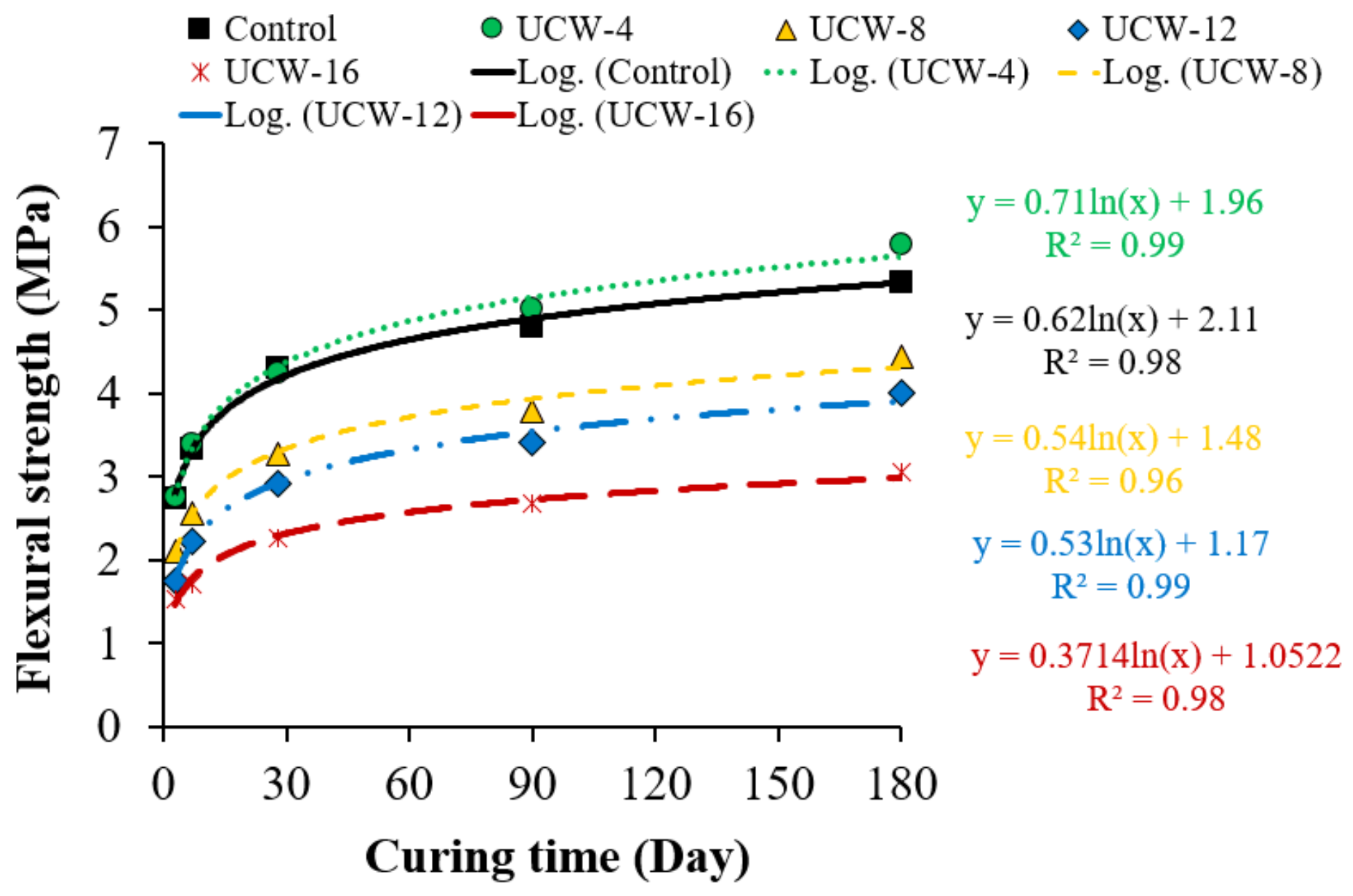

Figure 13

Relationship between curing time $(\mathrm{x})$ and flexural strength $(\mathrm{y})$ of mortar mixtures containing UCW in comparison with the control mix 


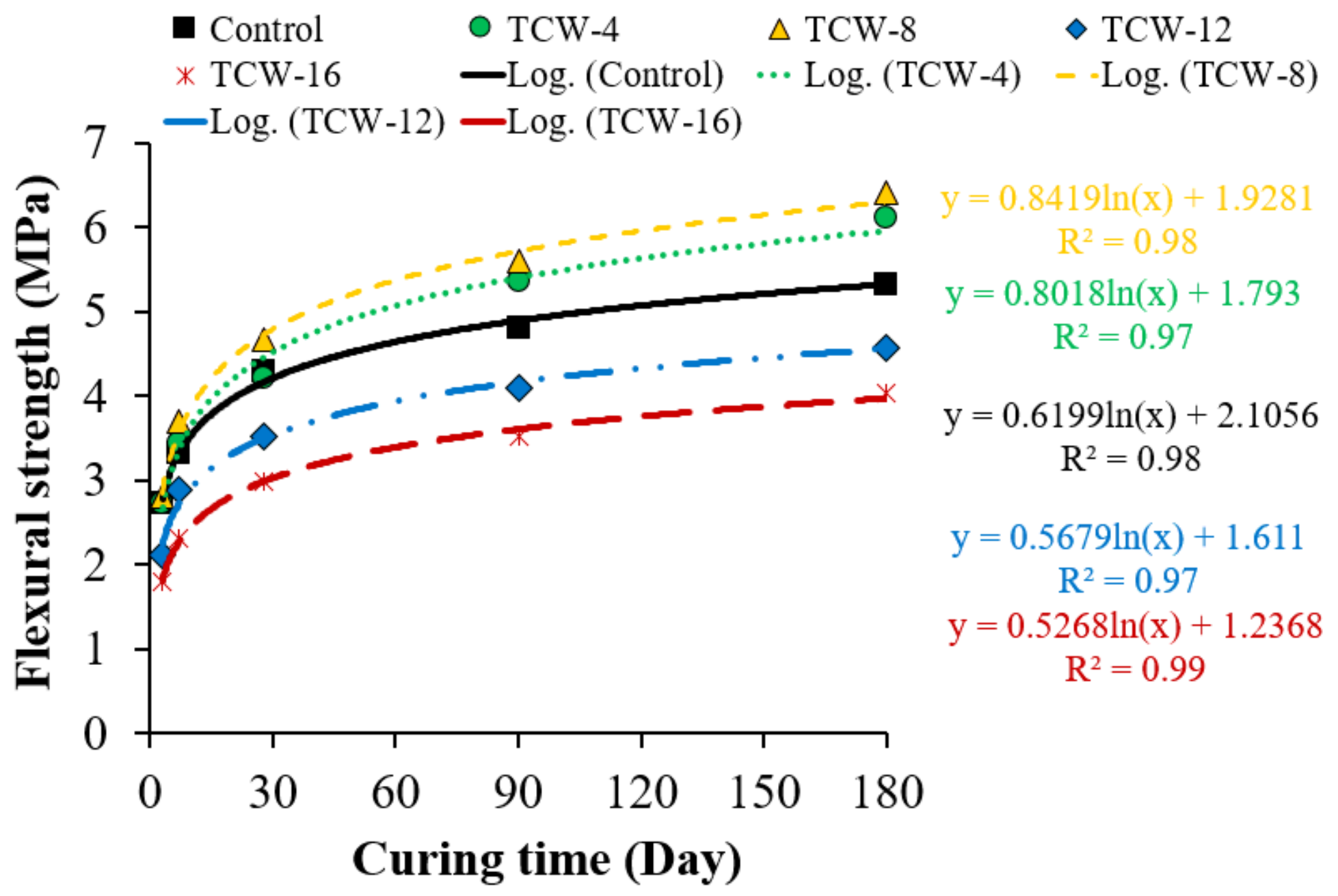

Figure 14

Relationship between curing time $(\mathrm{x})$ and flexural strength $(\mathrm{y})$ of mortar mixtures containing TCW in comparison with the control mix
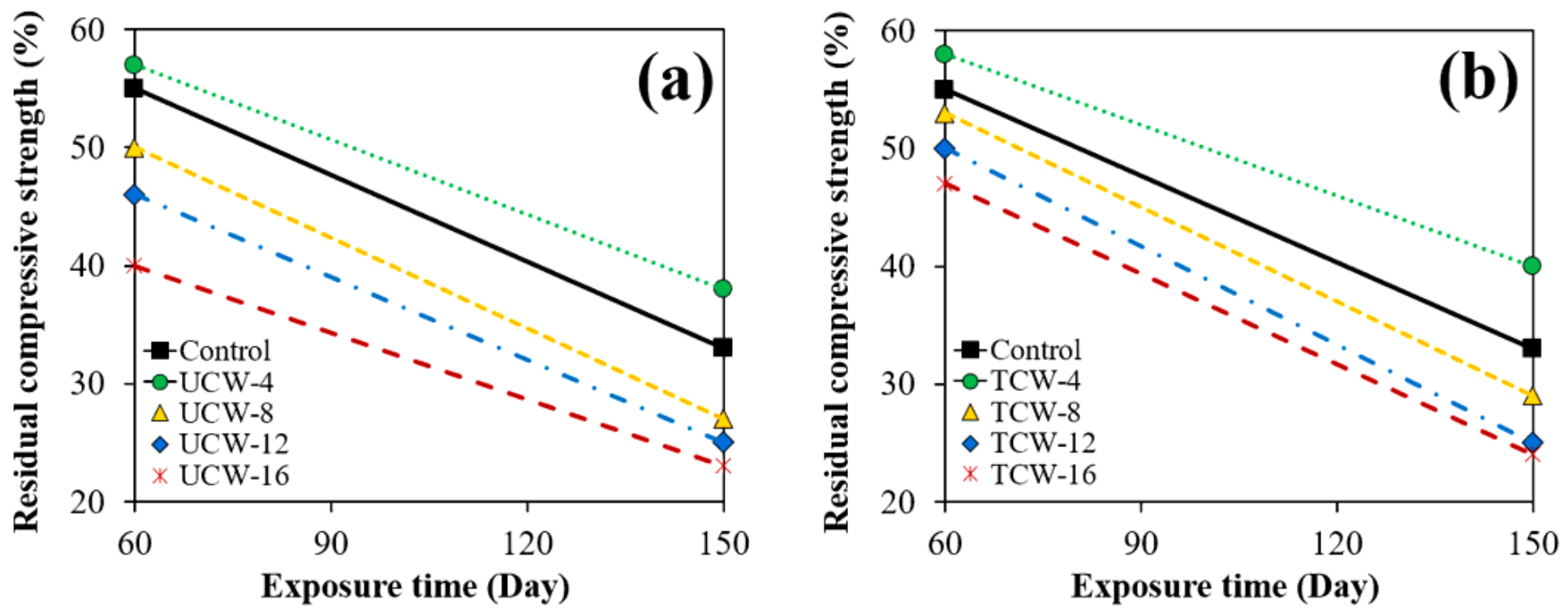

Figure 15 
Residual compressive strength of mortar samples after immersion in $3 \% \mathrm{H} 2 \mathrm{SO} 4$ solution
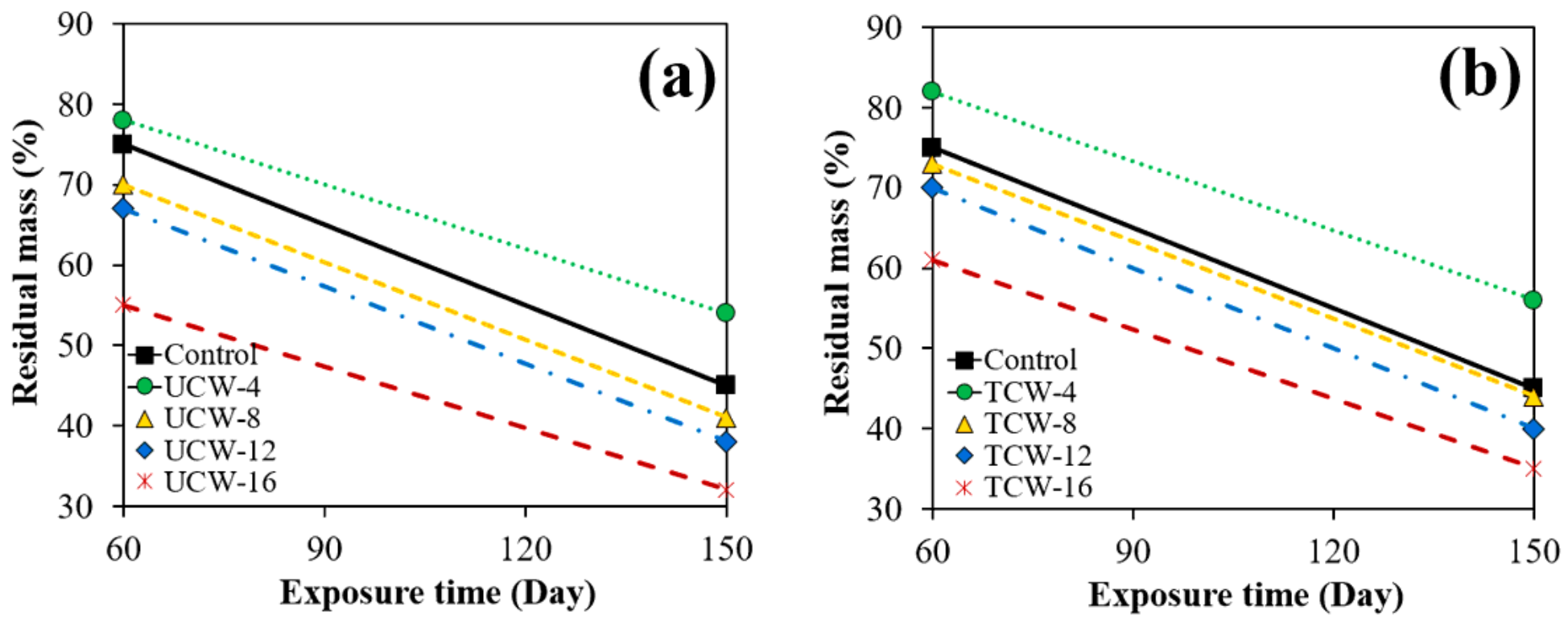

Figure 16

Residual mass of mortar samples after immersion in $3 \% \mathrm{H} 2 \mathrm{SO} 4$ solution 

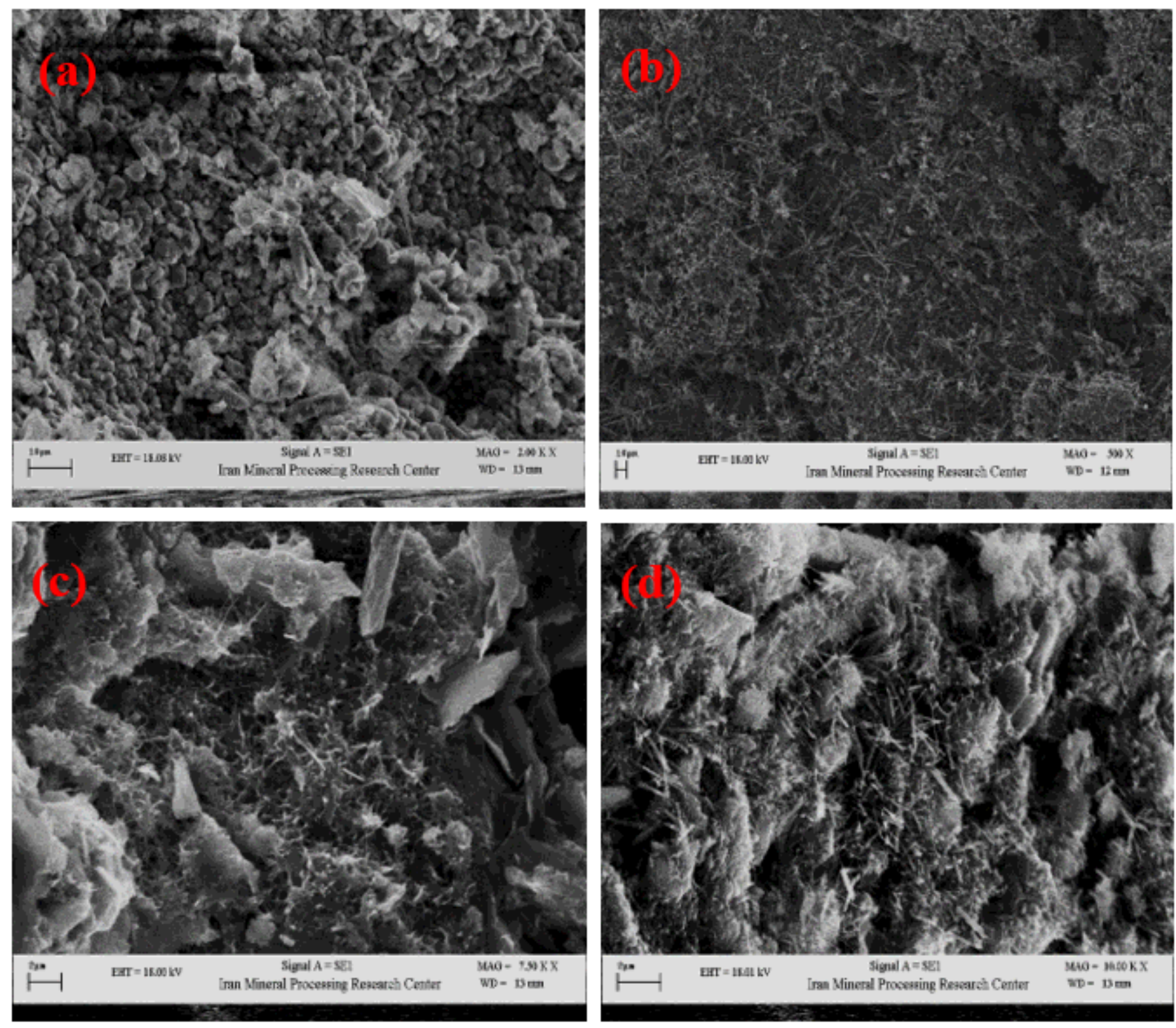

Figure 17

SEM images of 28-day mortar mixes containing (a) $0 \%$ SCMs (control), (b) $4 \%$ UCW (UCW-4), (c) $4 \%$ TCW (TCW-4), (d) and 8\% TCW (TCW-8) 

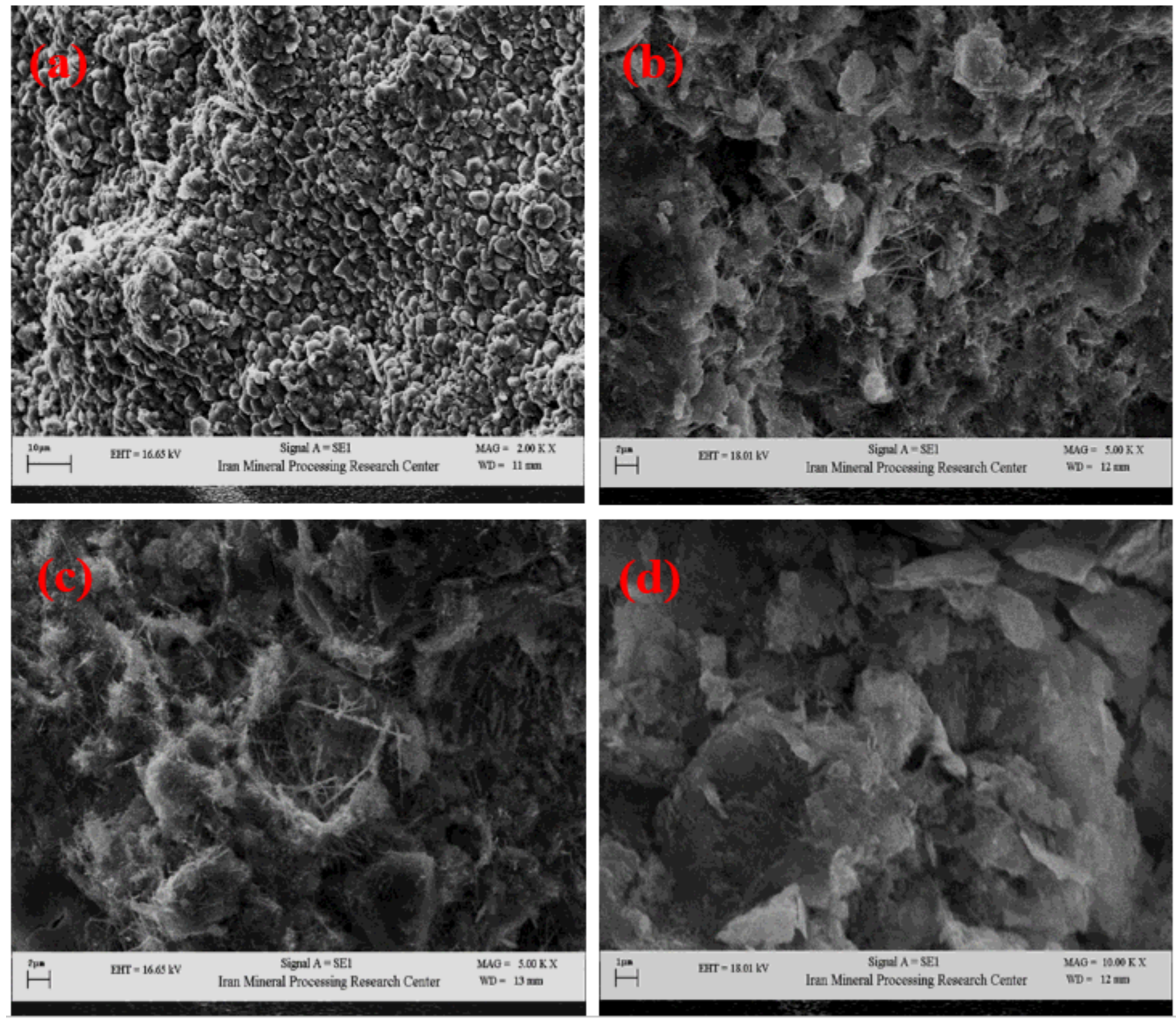

\section{Figure 18}

SEM images of 90-day mortar mixes containing (a) $0 \%$ SCMs (control), (b) $4 \%$ UCW (UCW-4), (c) 4\% TCW (TCW-4), (d) and 8\% TCW (TCW-8) 